\title{
Quaternary climate modulation of Pb isotopes in the deep Indian Ocean linked to the Himalayan chemical weathering
}

\author{
David J. Wilson $^{\mathrm{a}, \mathrm{b} *}$, \\ Albert Galy ${ }^{\mathrm{a}, \mathrm{c}}$, \\ Alexander M. Piotrowski ${ }^{\text {a }}$, \\ Virupaxa K. Banakar ${ }^{\mathrm{d}}$
}

a- Godwin Laboratory for Palaeoclimate Research, Department of Earth Sciences, University of Cambridge, Cambridge, CB2 3EQ, United Kingdom

b- Department of Earth Science and Engineering, Imperial College London, London SW7 2AZ, United Kingdom

c- Centre de Recherches Petrographiques et Geochimiques, CNRS-INSU-Nancy Université, BP 20, 54501 Vandoeuvre-lès-Nancy, France

d- CSIR-National Institute of Oceanography, Dona Paula, Goa, 403 004, India

* Corresponding Author. Tel.: +44 207594 6463. Email: david.wilson1@imperial.ac.uk

Word count: abstract 312, body text 7088, 86 references, 8 figures

Supplementary information: 2 figures and 5 tables

Revised for EPSL

$13^{\text {th }}$ March 2015 


\section{Abstract}

We use reductive sediment leaching to extract lead $(\mathrm{Pb})$ from the authigenic fraction of marine sediments and reconstruct the $\mathrm{Pb}$ isotope evolution of the deep central Indian Ocean over the past 250 thousand years at $\sim 3 \mathrm{kyr}$ resolution. Temporal variations define a binary mixing line that is consistent with data from ferromanganese nodules and which records mixing between two well-defined endmembers through time. The unradiogenic endmember appears to represent a widely-distributed $\mathrm{Pb}$ source, from mid-ocean ridges or possibly volcanic aerosols, while the radiogenic endmember coincides with the composition of Ganges-Brahmaputra river sediments that are indicative of the Himalayan weathering inputs. Glacial-interglacial $\mathrm{Pb}$ isotope variations are striking and can be explained by an enhancement of Himalayan contributions by two to three times during interglacial periods, indicating that climate modulates the supply of dissolved elements to the ocean. While these changes could accurately record variations in the continental chemical weathering flux in response to warmer and wetter conditions during interglacials, the relative proportions of $\mathrm{Pb}$ derived from the Ganges and Brahmaputra appear to have been constant through time. This observation may point towards particulate-dissolved interactions in the estuary or pro-delta as a buffer of short timescale variability in the composition (and potentially flux) of the fluvial inputs. In addition, the changes are recorded at $3800 \mathrm{~m}$ water depth, and with the lack of deep water formation in the Bay of Bengal, a mechanism to transfer such a signature into the deep ocean could either be reversible scavenging of dissolved $\mathrm{Pb}$ inputs and/or boundary exchange on the deep sea fan. Unless the mechanism transferring the $\mathrm{Pb}$ isotope signature into the deep ocean was itself highly sensitive to global climate cycles, and with the absence of a precessional signal in our $\mathrm{Pb}$ isotope data, we suggest that the Indian climate and its influence on basinscale chemical weathering were strongly modulated by glacial versus interglacial boundary conditions.

\section{Key words}

Indian Ocean, Ganges-Brahmaputra, Himalayan weathering, boundary exchange, lead isotopes, monsoon

\section{Highlights}

$>$ We reconstruct the $\mathrm{Pb}$ isotope evolution of the deep Indian Ocean 0-250 ka BP.

$>$ Control by binary mixing between volcanic and Ganges-Brahmaputra endmembers.

$>$ Reversible scavenging or boundary exchange transfer riverine $\mathrm{Pb}$ into deep ocean.

$>$ Quaternary climatic variations modulate dissolved element supply to the oceans.

$>$ Himalayan weathering flux enhanced by approximately 2-3 times during interglacials. 


\section{Introduction}

Continental weathering and erosion are fundamental processes that influence the earth's elemental cycles, ocean chemistry, atmospheric composition and climate (e.g. Raymo et al., 1988). However, potential feedbacks between climate and chemical weathering remain poorly understood because of the multiple controls on weathering rates (e.g. White and Blum, 1995; Dupre et al., 2003; Riebe et al., 2004; West et al., 2005). The Himalayan orogen, via the Ganges and Brahmaputra rivers, provides a significant source of both sediments $(\sim 1000$ million tons/year) and dissolved elements ( 100 million tons/year) to the oceans (Galy and France-Lanord, 1999; Milliman and Farnsworth, 2013), making it a good target for investigating climate-weathering links (note that for brevity, we are using 'weathering' to refer to the combined effect of in-situ chemical weathering and the dissolved transport of its products). Changes in Himalayan weathering have previously been invoked to explain changing ocean chemistry and climate during the Cenozoic (e.g. Edmond, 1992; Richter et al., 1992), but we lack direct evidence on its temporal evolution and its response to climate change over both million-year and glacial-interglacial timescales.

Past weathering rates may be obtained by analysing sedimentary archives recovered from the ocean basins. Isotopic tracers with oceanic residence times significantly longer than the mixing time of the oceans (e.g. $\mathrm{Sr}, \mathrm{Li}$ isotopes) can provide evidence on the globallyintegrated weathering signal over a timescale comparable to their residence time (Richter et al., 1992; Misra and Froelich, 2012). However, for any forcing occurring on timescales comparable to or shorter than their residence times, such tracers will show a muted amplitude of change and a phase lag behind that forcing (Richter and Turekian, 1993). In addition, these tracers cannot provide evidence on the geographic distribution of the weathering, making it difficult to link changes in weathering fluxes to specific continental source regions. For this purpose, we require isotopic tracers with oceanic residence times shorter than the mixing time of the oceans (e.g. Nd, Hf, $\mathrm{Pb}$ isotopes). Such tracers have a non-uniform geographical distribution that in part reflects the location of the inputs (von Blanckenburg, 1999; Frank, 2002; Goldstein and Hemming, 2003) and should respond rapidly to climatically-controlled changes in weathering inputs.

Since lead $(\mathrm{Pb})$ has a deep water residence time of $\sim 50-200$ years (Schaule and Patterson, 1981; Cochran et al., 1990; Henderson and Maier-Reimer, 2002), its isotopic composition is expected to be particularly sensitive to local weathering inputs. Lead isotope measurements on the authigenic fraction of marine sediments have therefore been used to trace regional weathering intensity and/or provenance through time (e.g. von Blanckenburg and Nagler, 2001; Reynolds et al., 2004; Foster and Vance, 2006; Haley et al., 2008; Gutjahr et al., 2009; Crocket et al., 2012). In the Indian Ocean, the Pb isotope signature advected by deep waters from the Southern Ocean is overwhelmed by local sources of $\mathrm{Pb}$ in the central Indian Ocean (Vlastelic et al., 2001), indicating the potential of $\mathrm{Pb}$ isotopes for tracing the local weathering sources. On million year timescales, Frank and O'Nions (1998) proposed a link between Himalayan weathering changes during the Neogene and the $\mathrm{Pb}$ isotopic composition of the deep central Indian Ocean recorded by ferromanganese crust SS663 (Figure 1). However, with the exception of a further study on crust DODO-232D (Frank et al., 2006), this approach remains under-exploited for investigating weathering in the Himalayan system, and in particular has not been applied on shorter timescales.

In this study, we reconstruct the $\mathrm{Pb}$ isotopic evolution of the deep Indian Ocean over glacial-interglacial and shorter timescales, aiming to better constrain the Himalayan $\mathrm{Pb}$ contribution and assess Himalayan weathering changes in response to glacial-interglacial cycles. More specifically, we (i) test the use of acid-reductive leaching to extract past seawater $\mathrm{Pb}$ isotopic composition from ocean sediments; (ii) reconstruct temporal variability 
in the $\mathrm{Pb}$ isotopic composition of the central Indian Ocean from 0-250 ka; (iii) assess the sources of $\mathrm{Pb}$ and the mechanisms for generating that temporal variability; and (iv) consider the implications of our high resolution record for past changes in the Himalayan weathering inputs.

\section{Regional setting}

Our study is based on two marine sediment cores from the deep central Indian Ocean (Figure 1). Core SK129-CR2 ( $3^{\circ} \mathrm{N}, 76^{\circ} \mathrm{E}, 3800 \mathrm{~m}$ water depth) is located on the east side of the Chagos-Laccadive Ridge in the Central Indian Basin (Banakar, 2005) and core ODP 758 $\left(5^{\circ} \mathrm{N}, 90^{\circ} \mathrm{E}, 2925 \mathrm{~m}\right.$ water depth) is located on Ninetyeast Ridge (Farrell and Janacek, 1991). Deep waters at both sites are supplied by northward-flowing Circumpolar Deep Water (CDW), which is transported from the Southern Ocean to the Central Indian Basin after crossing the Southeast Indian Ridge, either directly via the South Australia Basin or indirectly via the West Australia Basin and gaps in the Ninetyeast Ridge (Mantyla and Reid, 1995; You, 2000).

Both cores are located towards the distal limit of the Bengal Fan, but neither is directly influenced by the Bengal Fan sedimentation due to their elevated bathymetry, approximately $600 \mathrm{~m}$ and $1200 \mathrm{~m}$ respectively above the surrounding ocean floor. Therefore, they do not record (in any simple manner) the physical inputs of the Himalayan erosion, which are supplied via the Ganges-Brahmaputra river system to the Bengal Fan. However, because of their more proximal location, they appear well-placed to record an even greater influence of Himalayan weathering on the $\mathrm{Pb}$ isotopic composition of Indian Ocean seawater than previously observed in ferromanganese crusts SS663 and DODO-232D (Frank and O'Nions, 1998; Frank et al., 2006) (Figure 1).

\section{Materials and methods}

\subsection{Sampling and age models}

Lead isotopes were measured on bulk sediment acid-reductive leachates at 94 depths between $8-518 \mathrm{~cm}(5-251 \mathrm{ka} \mathrm{BP})$ in core SK129-CR2 (i.e. an average sampling resolution of $\sim 3 \mathrm{kyr})$ and at seven depths between 67-487 cm (33-249 ka BP) in core ODP 758. Both cores are dominated by carbonate ooze, with carbonate contents between 35-70 \% for SK129-CR2 and 50-70 \% for ODP 758 (Farrell and Janacek, 1991). The age model for SK129-CR2 is constrained by radiocarbon dates for $0-33 \mathrm{ka} \mathrm{BP}$, beyond which the benthic foraminiferal $C$. wuellerstorfi $\delta^{18} \mathrm{O}$ record is tuned to the LR04 benthic $\delta^{18} \mathrm{O}$ stack (Lisiecki and Raymo, 2005) at major marine isotope stage (MIS) boundaries (Supplementary Information; Tables S1-S3). For ODP 758, we use the most recently presented age model (Gourlan et al., 2010), which was also based on an orbitally-tuned $\delta^{18} \mathrm{O}$ record.

\subsection{Sediment leaching}

The authigenic component of the sediment was extracted by acid-reductive leaching, as described in Wilson et al. (2013). Briefly, bulk sediment samples of $\sim 5 \mathrm{~cm}^{3}$ were leached in $30 \mathrm{~mL} 0.44 \mathrm{M}$ acetic acid solution (buffered to $\mathrm{pH} 5$ by sodium acetate) in $50 \mathrm{~mL}$ centrifuge tubes on a rotating wheel. This process was repeated until lack of reaction demonstrated that carbonate had been removed. Samples were then washed at least twice with de-ionised water. The authigenic fraction was recovered by acid-reductive leaching for 1 hour in $30 \mathrm{~mL}$ of a pH 2 solution of $0.02 \mathrm{M}$ hydroxylamine hydrochloride $(\mathrm{HH})$ in $4.4 \mathrm{M}$ acetic acid. This $\mathrm{HH}$ leachate was centrifuged at $5000 \mathrm{rpm}$ for $10 \mathrm{~min}$ and decanted three times in sequence, before chemical separation and mass spectrometry. 
We recently demonstrated that the reproducibility of sediment leachate $\mathrm{Nd}$ isotope data can be sensitive to the solution/solid ratios used during the leaching procedure (Wilson et al., 2013), due to the removal of authigenic components during the decarbonation step and progressive exchange with volcanic components, if present. To test the sensitivity of $\mathrm{Pb}$ isotopes to such a process in this location, we leached different sample sizes at two core depths in SK129-CR2 (328 cm within MIS 6 and $424 \mathrm{~cm}$ within MIS 7), and also analysed a subset of nine leachates from MIS 6-7 using smaller solution/solid ratios in order to prevent complete decarbonation before $\mathrm{HH}$ leaching.

\subsection{Chemical purification and mass spectrometry}

Full analytical methods are contained in the Supplementary Information and summarised briefly here. The $\mathrm{Pb}$ fraction was separated using $\mathrm{HBr}-\mathrm{HCl}$ chemistry on AG1$\mathrm{X} 8$ anion exchange resin. The $\mathrm{Pb}$ isotopic composition was analysed on a $\mathrm{Nu}$ Plasma multicollector inductively-coupled plasma mass spectrometer (MC-ICP-MS) in the Department of Earth Sciences at the University of Cambridge, using thallium (Tl) as an internal standard to correct for mass fractionation (Hirata, 1996; Belshaw et al., 1998; Rehkamper and Mezger, 2000) according to an exponential law. Concentration-matched NIST-SRM-981 Pb standards were measured after approximately every five samples, and a linear correction was applied to all data measured in each analytical session to produce agreement with the accepted composition of NIST-SRM-981 Pb (Galer and Abouchami, 1998; Abouchami et al., 2000).

Our external reproducibility for each analytical session, assessed from the standard deviation $(2 \sigma)$ of repeat measurements of NIST-SRM-981, is in the range of 30-180 ppm for ${ }^{206} \mathrm{~Pb} /{ }^{204} \mathrm{~Pb}, 60-240 \mathrm{ppm}$ for ${ }^{207} \mathrm{~Pb} /{ }^{204} \mathrm{~Pb}$ and $50-250 \mathrm{ppm}$ for ${ }^{208} \mathrm{~Pb} /{ }^{204} \mathrm{~Pb}$. In addition, two internal standards (leachate samples that had been through column chemistry) were analysed in multiple analytical sessions over three years $(n=14-15)$ and yield typical long term reproducibility $(2 \sigma)$ of $140 \mathrm{ppm}$ for ${ }^{206} \mathrm{~Pb} /{ }^{204} \mathrm{~Pb}, 160 \mathrm{ppm}$ for ${ }^{207} \mathrm{~Pb} /{ }^{204} \mathrm{~Pb}$ and $190 \mathrm{ppm}$ for ${ }^{208} \mathrm{~Pb} /{ }^{204} \mathrm{~Pb}$. Replicates of 11 samples analysed in two separate sessions give results that are consistent with that external reproducibility (Table S4).

Full procedural blanks for the sediment leaching were $1.9 \pm 0.7 \mathrm{ng}(1 \sigma, \mathrm{n}=9)$. In comparison to leachate samples that contained 200-1000 ng $\mathrm{Pb}$, the blank contribution represents only $0.2-1.0 \%$ of the total $\mathrm{Pb}$, which in the worst case would generate an error of $\sim 100 \mathrm{ppm}$ for ${ }^{207} \mathrm{~Pb} /{ }^{204} \mathrm{~Pb}$ and $\sim 400 \mathrm{ppm}$ for ${ }^{206} \mathrm{~Pb} /{ }^{204} \mathrm{~Pb}$ and ${ }^{208} \mathrm{~Pb} /{ }^{204} \mathrm{~Pb}$. Since such errors are comparable to the external analytical reproducibility, and negligible in comparison to downcore variability, no blank correction has been applied.

\section{Results and discussion}

\subsection{Reconstructing past seawater Pb isotopic composition}

Our reconstruction of past seawater $\mathrm{Pb}$ isotopic composition is based on acidreductive leaching of bulk marine sediments which is used to extract the authigenic phases (Gutjahr et al., 2007; Martin et al., 2010; Wilson et al., 2013). The authigenic fraction is operationally-defined, but considered to be dominated by ferromanganese oxides formed in bottom water or shallow pore waters. This approach has been used in relatively few studies for $\mathrm{Pb}$ isotope reconstructions (e.g. Gutjahr et al., 2009; Stumpf et al., 2010; Crocket et al., 2012) and we have therefore investigated some important issues of the method; in particular, (i) the possibility for anthropogenic $\mathrm{Pb}$ contamination, and (ii) possible analytical artefacts related to the selectivity of the leaching procedure (Wilson et al., 2013). We summarise here the major outcomes of that assessment (see Supplementary Information) and further discuss the origin of the signal recorded by the authigenic phases. 


\subsubsection{Anthropogenic contamination}

The leachate $\mathrm{Pb}$ isotope data from SK129-CR2 record relatively smooth cyclical changes coinciding with glacial-interglacial cycles (Figure 2) and mostly fall on a binary mixing line in $\mathrm{Pb}-\mathrm{Pb}$ spaces (Figure 3). Within the depth range from $60-518 \mathrm{~cm}$, we have excluded six samples out of 82 with less radiogenic $\mathrm{Pb}$ isotopic compositions that are indicative of anthropogenic contamination with approximately the Broken Hill composition (Stacey et al., 1969) (Figures S1, S2). In addition, in the top section of the core $(8-56 \mathrm{~cm})$, the data are somewhat noisy (Figure 2) and those samples also deviate from the binary mixing line in a manner consistent with anthropogenic contamination (Figure S2). Since the magnitude of contamination required is considerably larger than expected from our procedural blanks, we suggest that such contamination occurred during coring or core storage. For the top section $(8-56 \mathrm{~cm})$, we have made a correction for each sample by regressing from the Broken Hill composition onto the best-fit binary mixing lines defined by the remaining 76 samples (Figure S2). That corrected data presents a smoother pattern of change across Termination I and a similar glacial-interglacial shift to that observed at previous terminations (Figure 2), suggesting that our correction is robust. Therefore, we show the corrected data from $8-56 \mathrm{~cm}$ in subsequent time series plots (but do not include that data in $\mathrm{Pb}-\mathrm{Pb}$ plots).

\subsubsection{Sediment leaching reproducibility}

Given evidence for a potential sample size effect on the $\mathrm{Nd}$ isotopic compositions of sediment leachates (Wilson et al., 2013), we tested the effect on $\mathrm{Pb}$ isotopic compositions at two core depths $(328 \mathrm{~cm}$ and $424 \mathrm{~cm})$. We see effects from $200 \mathrm{ppm}$ to $2600 \mathrm{ppm}$ on ${ }^{206} \mathrm{~Pb} /{ }^{204} \mathrm{~Pb},{ }^{207} \mathrm{~Pb} /{ }^{204} \mathrm{~Pb}$ and ${ }^{208} \mathrm{~Pb} /{ }^{204} \mathrm{~Pb}$ (Figure $\mathrm{S} 1$ ), representing on average $\sim 10 \%$ of the glacial-interglacial variability in the record. Since these tests represent a worst case scenario, they imply a generally reliable recovery of the authigenic $\mathrm{Pb}$ isotope signal. We also analysed a subset of nine samples without complete decarbonation before the leaching (Table S4) and these data are in excellent agreement with the decarbonated leachate data. The results of both tests are consistent with a mass balance argument that the recovery of authigenic compositions by sediment leaching should be more robust for $\mathrm{Pb}$ than $\mathrm{Nd}$ isotopes (Gutjahr et al., 2007).

We also observe good agreement between sediment leachate data from SK129-CR2 and ODP 758 (Figures 2,3). Since these cores are located in different settings with different local sediment inputs (Ahmad et al., 2005), the effect of any detrital or volcanic contamination during leaching would be expected to differ between the cores. Therefore, the similarity of both temporal changes and absolute values provides independent support for the reliable recovery of a regionally-controlled authigenic signature.

\subsubsection{Seawater origin of the authigenic signal}

Direct measurement of the natural $\mathrm{Pb}$ isotopic composition of seawater is not possible due to recent anthropogenic contamination (e.g. Schaule and Patterson, 1981; Alleman et al., 1999) and we therefore compare our sediment leachate data to measurements on the surface layers of ferromanganese crusts and nodules from the Indian Ocean (Frank and O'Nions, 1998; Vlastelic et al., 2001; Frank et al., 2006) (Figure 3). These substrates record a bottom water $\mathrm{Pb}$ isotope signature that was acquired over approximately the last $0.2-2 \mathrm{Ma}$, such that these measurements should record an integrated glacial-interglacial signal that is appropriate for comparison to our high resolution late Quaternary data.

Vlastelic et al. (2001) showed that $\mathrm{Pb}$ isotopes in surface scrapes of ferromanganese nodules from the central Indian Ocean (north of $20^{\circ} \mathrm{S}$; their N-Indian domain; Figure 1) plotted on a binary mixing line in all $\mathrm{Pb}-\mathrm{Pb}$ spaces (Figure 3), indicating mixing between two distinct sources of dissolved $\mathrm{Pb}$. Our leachate data from sediment cores SK129-CR2 and ODP 
758 show glacial-interglacial variability (Figure 2) that overlaps with the binary mixing line defined by those ferromanganese nodules (Figure 3), as well as extending to more radiogenic compositions during interglacials. The excellent agreement between the two datasets indicates that our record was influenced by the same two $\mathrm{Pb}$ sources as those crusts, which appears to confirm both the reliable recovery of an authigenic signal and its bottom water origin. This evidence also argues against a pore water control, or other in-situ controls, because in those cases such a well-defined binary mixing line would not be expected to be replicated between multiple nodules and sediment cores in different sedimentological environments across a large area of the Indian Ocean (Figure 1).

\subsection{Sources of Pb to the central Indian Ocean}

The binary mixing line defined by glacial-interglacial variability in SK129-CR2 (Figure 3) may be interpreted in terms of changes in the relative proportions of $\mathrm{Pb}$ supplied to seawater from two distinct sources. Potential sources include advection by ocean currents, dissolution of dust or aerosols, and more local riverine or sedimentary sources. Since that temporal variability is in good agreement with the spatial variability defined by ferromanganese crusts in the central Indian Ocean (Vlastelic et al., 2001), the $\mathrm{Pb}$ sources to deep water must be well defined in $\mathrm{Pb}-\mathrm{Pb}$ spaces and temporally rather constant. We therefore also require mechanisms to maintain constant endmember isotopic compositions through time, such as homogenisation by ocean circulation or large river systems.

At a global scale, dust may exert some control on seawater $\mathrm{Pb}$ isotopes (Jones et al., 2000; Ling et al., 2005), but dust maps (Mahowald et al., 2006) and modelling studies (Henderson and Maier-Reimer, 2002) suggest that dust input is unlikely to be important for $\mathrm{Pb}$ isotopes in the central Indian Ocean. Volcanic aerosols have been suggested as an important source of $\mathrm{Pb}$ to the Pacific Ocean (Jones et al., 2000; Klemm et al., 2007), but the strong geographic controls on Indian Ocean $\mathrm{Pb}$ isotopic variability appear to rule out such an aerosol source (Vlastelic et al., 2001). In particular, Vlastelic et al. (2001) observed distinct $\mathrm{Pb}-\mathrm{Pb}$ arrays in different regions of the Indian Ocean (Figure 3), with no endmember common to all arrays, pointing instead towards more local sources to each basin. Importantly, the NIndian domain does not overlap in $\mathrm{Pb}$ isotopic composition with the Antarctic-Indian domain (Figure 3), which is upstream in terms of deep water flow, ruling out the advection of $\mathrm{Pb}$ from the Southern Ocean or southern Indian Ocean as a control on $\mathrm{Pb}$ isotopes in the central Indian Ocean (von Blanckenburg et al., 1996; Vlastelic et al., 2001). Clearly, $\mathrm{Pb}$ is only advected over short path lengths in the deep Indian Ocean, reflecting its short oceanic residence time, and therefore the $\mathrm{Pb}$ sources must be more regional in extent.

\subsubsection{Radiogenic Pb endmember}

Figure 4 compares the SK129-CR2 leachate data to the compositions of suspended sediments from the Ganges, Brahmaputra and Lower Meghna rivers, which represent the major inputs to the Bay of Bengal in the northern Indian Ocean. Those sediments represent the bulk silicate fraction (after acetic acid leaching in order to remove any anthropogenic $\mathrm{Pb}$; see Supplementary Information) of the eroded crust at the catchment scale, presented in Millot et al. (2004) for the Ganges and Brahmaputra and characterised in this study for the Lower Meghna. Although the Lower Meghna sediment should record a mixture of its Ganges and Brahmaputra tributaries, its composition does not plot exactly on the mixing line between these endmembers, which may record the effect of mineralogical sorting and/or estuarine processes in a tide-dominated delta.

The key point here is that the Ganges-Brahmaputra riverine inputs are well placed in $\mathrm{Pb}-\mathrm{Pb}$ spaces to represent the radiogenic endmember for the binary mixing array defined by the SK129-CR2 leachates and N-Indian nodules. In particular, we suggest that the Lower 
Meghna estuarine sediments must play an important role in setting the isotopic composition of $\mathrm{Pb}$ inputs to the northern Indian Ocean (Figure 4). We also note that the leachate data from N-Indian nodules (Vlastelic et al., 2001) (Figure 4), with a more radiogenic average value, which is consistent with a Ganges-Brahmaputra source because SK129-CR2 is more proximally located to that source than those nodules (Figure 1).

A comparison to the $\mathrm{Pb}$ isotopic composition recently inferred for the Himalayan upper crust (Garcon et al., 2013) also supports that Himalayan Pb, homogenised by the Ganges-Brahmaputra-Meghna river system, represents the dominant radiogenic $\mathrm{Pb}$ source to the central Indian Ocean. However, in detail, and particularly for ${ }^{208} \mathrm{~Pb} /{ }^{204} \mathrm{~Pb}$, there is an offset between the compositions of the Himalayan crust and the Lower Meghna sediments (Figure 4), which could possibly reflect analytical differences in the Garcon et al. (2013) approach (such as a lack of acetic acid leaching to remove authigenic phases and/or an anthropogenic signal from the sediment) or uncertainty in their calculation to remove the effect of heavy minerals.

Two potential mechanisms may be important for transporting this Himalayan $\mathrm{Pb}$ signal into the deep ocean; either (i) particle scavenging of the dissolved riverine inputs and subsequent release in the deep ocean (Henderson and Maier-Reimer, 2002; Siddall et al., 2008), or (ii) boundary exchange with Himalayan erosion products on the deep sea Bengal Fan (Vlastelic et al., 2001; Lacan and Jeandel, 2005). Given the rapidity of reversible scavenging, the former mechanism implies a quite direct link between the Himalayan weathering inputs and the $\mathrm{Pb}$ isotopic composition of the deep ocean and should preserve climatic modulation at all frequencies. In contrast, if boundary exchange is the key mechanism, then the $\mathrm{Pb}$ isotopic composition of the Indian Ocean may only be linked indirectly to the Himalayan weathering. In detail, boundary exchange could operate through either particle scavenging of dissolved $\mathrm{Pb}$ in the Lower Meghna estuary or surface ocean, forming labile coatings on grains that subsequently release $\mathrm{Pb}$ into bottom water from the Bengal Fan, or by the direct dissolution of Himalayan erosion products after their arrival in the deep ocean. In either case, boundary exchange could potentially act as a low pass filter on the riverine signal. In that view, the rather smooth variations on glacial-interglacial timescales (Figure 2) could point towards boundary exchange as the key mechanism. However, recent models (Arsouze et al., 2009) and experiments (Pearce et al., 2013) advocate a rapid boundary exchange process on the timescale of months to decades.

\subsubsection{Unradiogenic Pb endmember}

The unradiogenic endmember for the central Indian Ocean appears harder to constrain. Volcanic aerosols could provide a globally well-mixed atmospheric source of unradiogenic $\mathrm{Pb}$ and their composition has been inferred indirectly from the leachable component of Chinese loess (Jones et al., 2000; Klemm et al., 2007). Based on their isotopic composition (Figure 5), we cannot rule out such aerosols as a potential unradiogenic endmember for the central Indian Ocean, but we consider them unlikely to be a major contributor because the Indian Ocean $\mathrm{Pb}-\mathrm{Pb}$ arrays defined by ferromanganese nodules (Vlastelic et al., 2001) do not converge on such a common endmember (Figure 3). Instead, we suggest that a more regional volcanic source supplies unradiogenic $\mathrm{Pb}$ to the deep central Indian Ocean. Although there is wide variability between individual basalt samples, the mean composition of mid-ocean ridge basalt (MORB) from the Indian Ocean (Iwamori et al., 2010) is consistent with the required unradiogenic $\mathrm{Pb}$ source (Figure 5). The temporal constancy may in this case reflect averaging of a large number of small $\mathrm{Pb}$ sources and homogenisation by ocean circulation.

The exact mechanism involved in supplying $\mathrm{Pb}$ from the volcanic ridges is uncertain, but it may arise from the interaction between seawater and widely distributed volcanic 
seafloor sediments, or could instead be concentrated where deep waters flow through fractures in the ridges along their pathway into the central Indian Ocean. For example, basalts of the Southeast Indian Ridge at $120-125^{\circ} \mathrm{E}$, which is the location of the major deep inflow (Mantyla and Reid, 1995), or more locally those of the Central Indian Ridge, have suitable Pb isotopic compositions to represent this endmember (Figure 5). Evidence is emerging that hydrothermal plumes provide a significant source of soluble iron to the deep ocean, including along the Central Indian Ridge (Nishioka et al., 2013), which suggests that they may also be an important $\mathrm{Pb}$ source. Such a hydrothermal source of $\mathrm{Pb}$ is further supported by the $\mathrm{Pb}$ isotope compositions of hydrothermal-influenced ferromanganese nodules collected in proximity to the Indian Ocean ridges (Vlastelic et al., 2001). Those samples fall along a mixing line that is consistent with their derivation primarily from a local MORB source, with a lesser contribution from $\mathrm{Pb}$ scavenged from ambient seawater (Figure 5).

354

355

356

357

358

359

360

361

362

363

364

365

366

367

368

369

370

371

372

373

374

375

376

377

378

379

380

381

382

383

384

385

386

387

388

389

390

391

\subsubsection{Evidence against incongruent weathering}

$\mathrm{The} \mathrm{Pb}$ isotopic composition of inputs to the ocean may also be influenced by isotopic fractionation during incongruent weathering (e.g. Erel et al., 1994; Harlavan and Erel, 2002), through the preferential dissolution of highly radiogenic minerals or the preferential mobilisation of radiogenic $\mathrm{Pb}$ isotopes from radiation-damaged sites in minerals. Either process could lead to a decoupling between the $\mathrm{Pb}$ isotopic composition of the detrital sedimentary inputs and that released to solution, as a function of weathering mechanism or intensity (e.g. von Blanckenburg and Nagler, 2001; van de Flierdt et al., 2002; Reynolds et al., 2004; Foster and Vance, 2006; Gutjahr et al., 2009). However, those observations were predominantly made in glaciated regions of the North Atlantic and a number of observations suggest that incongruent dissolution is not an important effect in the Indian Ocean:

(i) A single binary mixing line defines both the spatial mixing in nodule data from the N-Indian domain of Vlastelic et al. (2001) and the glacial-interglacial mixing in cores SK129-CR2 and ODP 758 (Figure 3), suggesting a constancy of the Pb sources through time. It seems highly unlikely that incongruent weathering, which could potentially control temporal changes, would produce the same trend in $\mathrm{Pb}-\mathrm{Pb}$ spaces as mixing, which controls the spatial pattern.

(ii) The Himalayan crustal inputs inferred from Lower Meghna riverine sediment compositions are well located in $\mathrm{Pb}-\mathrm{Pb}$ spaces to define the radiogenic $\mathrm{Pb}$ endmember for deep central Indian Ocean seawater (Figure 4) if the weathering is close to congruent.

(iii) Whereas a shift towards more radiogenic $\mathrm{Pb}$ isotopes in North Atlantic ferromanganese crusts at the onset of Northern Hemisphere glaciation has been attributed to incongruent weathering (von Blanckenburg and Nagler, 2001), no comparable shift is seen in Indian Ocean crusts at the onset of glaciation over the Himalayas (Frank, 2002).

Such evidence against a control by incongruent weathering supports our description of Indian Ocean seawater $\mathrm{Pb}$ isotopic composition in terms of mixing between Himalayan and volcanic endmembers, with approximately unchanging compositions through time that are well characterised by the composition of the measured solid phases.

\subsection{Climate modulation of Pb isotopes through glacial-interglacial cycles}

The benthic oxygen isotope record from SK129-CR2 reflects the combined influences of global sea level, deep sea temperature and hydrography, and therefore provides a good reference frame for the approximate timing of glacial and interglacial periods (Figure 6). In that context, there is a clear climatic modulation of the $\mathrm{Pb}$ isotopes at the $\sim 3 \mathrm{kyr}$ resolution of our record. Lead isotopes were more radiogenic during interglacial than glacial periods (Figure 6), indicating that an increased proportion of $\mathrm{Pb}$ at these times was derived from Himalayan weathering products via the Ganges-Brahmaputra (Figure 4). 
We first consider whether changes in the northward advection of the unradiogenic volcanic $\mathrm{Pb}$ signature by bottom currents could have influenced the records at SK129-CR2 and ODP 758. At present, the evidence on glacial versus interglacial flow speeds in the deep Indian Ocean is rather limited, being restricted to the western basins, but points towards flow speeds that were similar or slightly stronger during interglacial than glacial periods (McCave et al., 2005; Thomas et al., 2007). In that case, we would require a major decrease in the volcanic $\mathrm{Pb}$ flux released from the ocean floor during interglacials in order to explain the more radiogenic values seen in the record at this time. Instead, we suggest that the volcanic $\mathrm{Pb}$ sources were most likely approximately constant through time, and infer that the temporal changes predominantly record changes in the continentally-derived source. In that scenario, climatic modulation could arise from either increased Himalayan weathering inputs or increased boundary exchange with Himalayan sediments during interglacials.

Interglacial periods were characterised by lower sedimentation rates at SK129-CR2 and lower productivity in the region (Rostek et al., 1997; Punyu et al., 2014), both of which may have decreased boundary exchange locally and reduced the Himalayan imprint in the deep ocean. Deep waters were also better oxygenated during interglacials (Pattan and Pearce, 2009), which may also have decreased boundary exchange if this process is enhanced by reducing conditions. We also provided evidence from $\mathrm{Nd}$ isotopes for a rather constant boundary exchange process between glacial and interglacial periods in the western Indian Ocean (Wilson et al., 2012). Therefore, even if boundary exchange is important for transferring the Himalayan weathering signature into the deep ocean, it appears hard to explain the SK129-CR2 Pb isotope record by oceanic controls on that boundary exchange process.

Alternatively, if reversible scavenging of the dissolved inputs was the important mechanism transferring the Himalayan signature to our sites, then sediment fluxes into the Bay of Bengal may also have contributed to the observed changes. To the extent that existing records from the Bengal Fan are representative of the whole fan, sedimentation rates appear to have been elevated during interglacials (Goodbred, 2003), which may have enhanced particle scavenging on the fan and reduced the surface ocean residence time of $\mathrm{Pb}$. Therefore, this process also appears to work in the wrong direction to explain the observed changes, because it would have restricted the $\mathrm{Pb}$ supply reaching our deep open ocean sites during interglacial periods.

Instead, since the Himalayan basin experienced warmer and wetter conditions during interglacial than glacial periods (Kudrass et al., 2001; Galy et al., 2008; Caley et al., 2011), we suggest that our $\mathrm{Pb}$ isotope record is predominantly recording significantly elevated continental weathering fluxes during interglacials. In particular, the coincidence with salinity changes in the Bay of Bengal (Kudrass et al., 2001; Figure 6e) and dust-based aridity reconstructions from the Arabian Sea (Caley et al., 2011; Figure 6c) suggests that precipitation and runoff were important controls on those weathering inputs. Our proposed weathering mechanism is also in agreement with the recent study of Lupker et al. (2013), which provided independent evidence for elevated Himalayan weathering during the Holocene compared to the Last Glacial Maximum based on mobile element depletion and hydration extent in the solid erosion products on the Bengal Fan. According to Lupker et al. (2013), Himalayan weathering predominantly occurs on the Ganges-Brahmaputra floodplains, and such an environment would likely have been highly sensitive to climatic change.

It is worth emphasising one further point, which is that the well-defined binary mixing line in our seawater reconstructions also appears to constrain that the proportions of dissolved $\mathrm{Pb}$ derived from the Ganges and Brahmaputra catchments were constant through time (Figure 4). It seems perhaps surprising that the weathering changes described above should have occurred uniformly over such a large spatial scale, although that interpretation has been made 
for the physical erosion based on detrital sediment provenance (Lupker et al., 2013). Alternatively, this observation may reflect the mechanism by which the Himalayan $\mathrm{Pb}$ signal is transferred to the Indian Ocean. If the Himalayan $\mathrm{Pb}$ signature is transferred to seawater through particulate-dissolved interaction from the Lower Meghna estuary to the pro-delta, then sediment mixing and remobilisation could act to average and smooth any short timescale temporal variability in the proportions of Ganges and Brahmaputra inputs.

\subsubsection{Quantification of weathering changes}

In this section, we use a simple isotope mass balance based on binary mixing between a Himalayan endmember (Lower Meghna sediments) and an Indian Ocean MORB endmember to provide semi-quantitative constraints on the proposed weathering changes (Figure 7). Based on those endmembers, we infer that the proportion of Himalayan $\mathrm{Pb}$ at the location of SK129-CR2 increased from $~ 70 \%$ during glacial periods to $85-90 \%$ during interglacial periods (Figure 7a). With the further assumption of unchanging volcanic $\mathrm{Pb}$ fluxes through time, we estimate that the Himalayan $\mathrm{Pb}$ fluxes were enhanced by a factor of two or more throughout interglacial compared to glacial periods, and by up to 3.5 times for short periods of the Holocene and MIS 7 (Figure 7b). That simple calculation also assumes that there was no change in deep ocean current strength and no change in the extent of nonconservative behaviour through processes such as particle scavenging.

Given the possibility of temporal changes in the processes affecting $\mathrm{Pb}$ transport to our site, we suggest that our evidence may only provide a semi-quantitative estimate of Himalayan weathering fluxes. Nevertheless, it is instructive to compare our estimate to the recent estimate of Lupker et al. (2013) that was based on potassium (K) depletion in detrital sediments from the Bengal Fan. In their simplest scenario, they inferred a three-fold enhancement of Himalayan weathering fluxes between the Last Glacial Maximum and the Holocene, with two-fold to 10 -fold enhancements also possible depending on assumptions about detrital sediment fluxes and other uncertainties in their model. Despite the different approaches of the two studies, there is a good agreement between our estimate (Figure 7) and their lower end estimates. In fact, our approach is quite complementary to that of Lupker et al. (2013) because it does not require that detrital sedimentation rates are known and it does not assume or require a steady state. Therefore, agreement between the two studies suggests that in each case the model assumptions were reasonable to provide a first order reconstruction of weathering fluxes. We further note that using the average value of the Lower Meghna for K depletion, rather than the 0-2 ka sediment core interval used by Lupker et al. (2013), would enhance the inferred changes in weathering fluxes from LGM to modern by another $25 \%$ and, while keeping the $\mathrm{Pb}$-based and K-based estimates within error, could hint at a non steady state for the riverine sediments that is likely driven by anthropogenic forcing.

Any estimate of weathering fluxes based on a single element or isotope system is potentially biased towards mineral phases in which that element is concentrated. The reconstruction based on $\mathrm{K}$ depletion was attributed to predominantly biotite weathering (Lupker et al., 2013), but may be broadly indicative of silicate weathering fluxes. For Pb, which is mostly contained in clays, feldspars and micas (Garcon et al., 2014), silicate weathering will also be the main control. Unfortunately, the anthropogenic contribution to dissolved $\mathrm{Pb}$ in modern river catchments precludes the determination of the $\mathrm{Pb} /$ cation ratio released by weathering as a function of weathering intensity, but the close agreement between our estimates of weathering fluxes from $\mathrm{Pb}$ isotopes and those derived from the cations (Lupker et al., 2013) suggests only a small variation in the Pb/cation ratios in the continental dissolved load over the range of observed changes in weathering intensity, which is also supported by the lack of evidence for incongruent $\mathrm{Pb}$ release based on isotopic data (Section 4.2.3). One clear outcome from the comparison between the two studies is that Himalayan 
weathering changes of at least a factor of two between glacial and interglacial periods are required.

It has previously been suggested that neodymium $(\mathrm{Nd})$ isotopes in this part of the Indian Ocean may also provide evidence of enhanced Himalayan weathering inputs during interglacial periods (Burton and Vance, 2000; Stoll et al., 2007; Gourlan et al., 2010). However, more recent evidence demonstrates that those $\mathrm{Nd}$ isotope records correspond to a deep water rather than a surface water signal (Tachikawa et al., 2013). In that case, given the significantly longer oceanic residence time of $\mathrm{Nd}$ than $\mathrm{Pb}$ (Frank, 2002; Goldstein and Hemming, 2003), those records are subject to significant modulation by the water mass composition advected from the Southern Ocean (Frank and O'Nions, 1998; Frank et al., 2006). In particular, over the last glacial cycle the evolution of the deep Indian Ocean is almost identical to that of the deep South Atlantic core RC11-83 (Piotrowski et al., 2009). Therefore, although there is a broad agreement between our $\mathrm{Pb}$ isotope record and those $\mathrm{Nd}$ isotope records on a glacial-interglacial timescale, we argue that they are predominantly responding to glacial-interglacial forcing through independent processes. The strength of our $\mathrm{Pb}$ isotope approach is that the multiple isotopes provide strong constraints on $\mathrm{Pb}$ sources, while the short residence time of $\mathrm{Pb}$ (and low deep ocean concentration) make it sensitive to local sources and insensitive to long path length advection, as previously demonstrated by Vlastelic et al. (2001) and discussed earlier.

\subsection{Relationship with the Indian monsoon}

In contrast to the glacial-interglacial changes, there is no evidence for precessional ( $23 \mathrm{kyr}$ ) or sub-orbital controls on our $\mathrm{Pb}$ isotope record, which shows a surprisingly smooth pattern of changes (Figure 6). This observation contrasts with continental climate reconstructions from southeast Asian speleothems (Wang et al., 2001; Wang et al., 2008; Cheng et al., 2009), which are dominated by precessional forcing in phase with Northern Hemisphere summer insolation (Figure 6). These speleothem oxygen isotope records were interpreted in terms of variability of the East Asian Summer Monsoon, but may also reflect changes in the Indian Summer Monsoon (Dong et al., 2010; Pausata et al., 2011). Marine reconstructions of the Indian Summer Monsoon (e.g. Caley et al., 2011) also show a precessional signature, although with different phasing (Figure 6). Since the Indian Summer Monsoon is expected to influence precipitation patterns in the region, the lack of precessional variability in the $\mathrm{Pb}$ isotope record from SK129-CR2 seems a surprising result.

We first consider whether precessional and shorter timescale variability in weathering inputs could be smoothed before being recorded in our record. One potential smoothing process could involve sediment recycling and reversible exchange in the floodplains, but recent studies have suggested a short timescale for fine-grained sediment transfer within the Ganges basin, on the order of 0.5-1.5 kyr (Galy and Eglinton, 2011; Lupker et al., 2012). Therefore, such processes should not be responsible for any significant smoothing at the $\sim 3$ kyr resolution of the SK129-CR2 record. Sea level change could potentially influence the remobilisation of sediments and the dynamics of estuarine and/or delta front particulatedissolved interactions, influencing the transfer of riverine $\mathrm{Pb}$ to seawater. However, the $\mathrm{Pb}$ isotope record changes closely in phase with the glacial-interglacial climate transitions inferred from benthic oxygen isotopes, with no apparent lag or smoothing on timescales of a few thousand years (Figure 6), suggesting that such a process should not have been capable of obscuring precessional timescale variability if it had been present.

In the absence of evidence for smoothing processes on longer than millennial timescales, we consider that the lack of a precessional signature is a real feature of our record. With the exception of the Chinese speleothem records, many previous monsoon reconstructions have been restricted to Termination I, where both precessional and glacial- 
interglacial forcing were combined, whereas the climate evolution in the Himalayan basin over longer timescales remains rather poorly constrained. In the case of a recent reconstruction of the Indian continental climate from grain size analysis in Arabian Sea core MD04-2861 (Caley et al., 2011) (Figure 6c), significant glacial-interglacial changes in aridity are inferred whereas precessional variability is somewhat muted. If that record is representative of the regional climate, then it appears to support that changes in the Himalayan weathering flux were indeed closely coupled to precipitation and/or temperature change. In other words, the Indian monsoon strength may have been strongly modulated by glacial boundary conditions, such that the Indian continental climate and associated weathering fluxes were dominated by the glacial-interglacial forcing.

\subsection{Reassessment of the Himalayan inputs over the last $25 \mathrm{Ma}$}

Having argued above that continental weathering exerted a major control on the glacial-interglacial $\mathrm{Pb}$ isotope variability, and given the similar magnitude of change in $\mathrm{Pb}$ isotopes between the early Miocene and present (Figure 8), it is tempting to transfer our weathering interpretation to the longer timescale evolution of this system. Such a perspective could potentially provide evidence on climate-weathering feedbacks over million year timescales, as well as the influence of Himalayan tectonics on weathering.

The original proposal that ferromanganese crusts SS663 and DODO-232D (Figure 1) recorded enhanced Himalayan inputs at 20-8 Ma (Frank and O'Nions, 1998; Frank et al., 2006) was based on elevated ${ }^{208} \mathrm{~Pb} /{ }^{206} \mathrm{~Pb}$ ratios in that interval (Figure 8). However, the $\mathrm{Pb}$ isotope data now available from Himalayan river sediments and our new evidence from SK129-CR2 and ODP 758 together demonstrate that ${ }^{206} \mathrm{~Pb} /{ }^{204} \mathrm{~Pb}$ ratios (or other ratios to ${ }^{204} \mathrm{~Pb}$ ) are more appropriate for tracing the Himalayan inputs (Figure 4). Considering the modern Himalayan sources, ${ }^{208} \mathrm{~Pb} /{ }^{206} \mathrm{~Pb}$ actually decreases when ${ }^{206} \mathrm{~Pb} /{ }^{204} \mathrm{~Pb}$ increases to accompany increased Himalayan inputs (Figure 8). Therefore, it appears that the Himalayan signature recorded in those crusts started to increase at $\sim 14 \mathrm{Ma}$ and continued to increase, possibly stepwise, towards a maximum at $\sim 2$ Ma that has persisted to the present day.

There is therefore a contrast between elevated Himalayan inputs during warm interglacial periods of the Quaternary, and increasing Himalayan inputs from $~ 14-2 \mathrm{Ma}$ (Figure 8) during a time of predominantly global cooling. If interpreted in terms of weathering changes, the implication is that factors other than climate, such as tectonics and the associated rock uplift and physical denudation (Riebe et al., 2001), may have provided the major controls on Himalayan weathering inputs over these long timescales. Indeed, given dating uncertainties for ferromanganese crusts (Nielsen et al., 2011), the inferred increase in Himalayan weathering since $\sim 14$ Ma may have been coincident with enhanced Himalayan exhumation and erosion starting $\sim 15 \mathrm{Ma}$ (Clift et al., 2008). This evidence could possibly indicate a switch between a kinetic (climate) control over short (kyr) timescales and a supply control related to tectonic uplift and denudation over longer (Myr) timescales. However, the inferred decrease in Himalayan erosion rates from 10-3 Ma (Clift et al., 2008) does not appear to be recorded in those $\mathrm{Pb}$ isotope records. The paucity of reliable mass accumulation rates for the entire Bengal Fan could cast some doubts on such inferences on Himalayan erosion rates over this period, or alternatively this observation may point towards multiple controls on this system that are not yet fully understood.

In particular, when considering such long timescales, a number of other factors could influence those ferromanganese crust records in addition to continental weathering fluxes. For example, the shift towards more radiogenic $\mathrm{Pb}$ isotopes could record an increasing proximity of the crusts to the Ganges-Brahmaputra source or changes in the radiogenic $\mathrm{Pb}$ endmember due to exhumation of the Lesser Himalayas within the Himalayan orogen. Changes in the volcanic $\mathrm{Pb}$ source, or in the pattern and/or strength of ocean currents, could also play a role, 
but are poorly constrained on these timescales. Therefore, future studies should aim to provide better constraints on the changing locations of seawater archives in relation to sediment sources and on potential changes in sediment source compositions. Records from multiple locations could also help to better constrain the transport processes transferring the Himalayan $\mathrm{Pb}$ signature into the deep ocean and the possible role of marine processes in modulating the $\mathrm{Pb}$ isotope signal.

\section{Conclusions}

Lead isotope reconstructions from sediment leachates in the deep central Indian Ocean are in good agreement with data from spatially-distributed ferromanganese nodules (Vlastelic et al., 2001) and ferromanganese crust records (Frank and O'Nions, 1998; Frank et al., 2006), confirming the suitability of sediment leaching approaches for reconstructing past bottom water $\mathrm{Pb}$ isotopic compositions. Temporal variations during the last $250 \mathrm{ka}$ define a binary mixing line in $\mathrm{Pb}-\mathrm{Pb}$ spaces, indicating a control by two major $\mathrm{Pb}$ sources to the central Indian Ocean with approximately constant endmember compositions through time. The unradiogenic endmember appears to represent a well-mixed source of $\mathrm{Pb}$, likely from volcanic ridge inputs, while the radiogenic endmember corresponds to the composition of river sediments of the Lower Meghna, transferred into the deep ocean by reversible scavenging and/or boundary exchange. This observation supports the hypothesis of Frank and O'Nions (1998) that $\mathrm{Pb}$ supplied from the Himalayas influences the deep water $\mathrm{Pb}$ isotopic composition in the central Indian Ocean.

Glacial-interglacial variability in Indian Ocean $\mathrm{Pb}$ isotopic composition from $0-250 \mathrm{ka}$ BP is striking and can be explained by a two- to three-fold enhancement of Himalayan inputs during interglacials. In the simplest case, that record is potentially recording changes in continental weathering fluxes that were strongly modulated by climate, consistent with evidence from a recent independent approach (Lupker et al., 2013). However, a number of uncertainties remain, including the possible role of particulate-dissolved interactions in buffering short timescale variability in the $\mathrm{Pb}$ isotopic composition and/or flux of the fluvial inputs, and the oceanic transport of $\mathrm{Pb}$. In order to fully exploit this approach, and especially to understand the longer timescale evolution of the system, we need to better constrain the mechanisms transferring the Himalayan signature into the deep ocean, as well as spatial and temporal patterns in $\mathrm{Pb}$ isotope distribution.

\section{Acknowledgments}

We thank Jo Clegg and Jason Day for help keeping the clean lab and MC-ICP-MS running, and Oliver Shorttle for assistance with $\mathrm{Pb}$ isotope data reduction. We also thank two reviewers for their valuable comments which helped us improve the manuscript. The sediment core was collected on board ORV Sagar Kanya of the Ministry of Earth Sciences, India. This study was supported by a NERC studentship to DJW and NERC Grant NE/F006047/1, RG50124 to AMP/AG. 


\section{References}

634

635

636

Abouchami, W., Galer, S.J.G., Hofmann, A.W., 2000. High precision lead isotope systematics of lavas from the Hawaiian Scientific Drilling Project. Chemical Geology 169, 187-209.

Ahmad, S.M., Babu, G.A., Padmakumari, V.M., Dayal, A.M., Sukhija, B.S., Nagabhushanam, P., 2005. Sr, Nd isotopic evidence of terrigenous flux variations in the Bay of Bengal: Implications of monsoons during the last $\sim 34,000$ years. Geophys. Res. Lett. 32, doi: 10.1029/2005gl024519.

Alleman, L.Y., Veron, A.J., Church, T.M., Flegal, A.R., Hamelin, B., 1999. Invasion of the abyssal North Atlantic by modern anthropogenic lead. Geophys. Res. Lett. 26, 1477-1480.

Arsouze, T., Dutay, J.C., Lacan, F., Jeandel, C., 2009. Reconstructing the Nd oceanic cycle using a coupled dynamical - biogeochemical model. Biogeosciences 6, 2829-2846.

Banakar, V.K., 2005. $\delta^{13} \mathrm{C}$ depleted oceans before the Termination 2: More nutrient-rich deep-water formation or light-carbon transfer? Indian J. Mar. Sci. 34, 249-258.

Belshaw, N.S., Freedman, P.A., O'Nions, R.K., Frank, M., Guo, Y., 1998. A new variable dispersion double-focusing plasma mass spectrometer with performance illustrated for $\mathrm{Pb}$ isotopes. Int. J. Mass Spectrom. 181, 51-58.

Berger, A., Loutre, M.F., 1991. Insolation values for the climate of the last 10 million years. Quat. Sci. Rev. 10, 297-317.

Burton, K.W., Vance, D., 2000. Glacial-interglacial variations in the neodymium isotope composition of seawater in the Bay of Bengal recorded by planktonic foraminifera. Earth Planet. Sci. Lett. 176, 425-441.

Caley, T., Malaize, B., Zaragosi, S., Rossignol, L., Bourget, J., Eynaud, F., Martinez, P., Giraudeau, J., Charlier, K., Ellouz-Zimmermann, N., 2011. New Arabian Sea records help decipher orbital timing of Indo-Asian monsoon. Earth Planet. Sci. Lett. 308, 433-444.

Cheng, H., Edwards, R.L., Broecker, W.S., Denton, G.H., Kong, X.G., Wang, Y.J., Zhang, R., Wang, X.F., 2009. Ice Age terminations. Science 326, 248-252.

Clift, P.D., Hodges, K.V., Heslop, D., Hannigan, R., Van Long, H., Calves, G., 2008. Correlation of Himalayan exhumation rates and Asian monsoon intensity. Nat. Geosci. 1, 875-880.

Cochran, J.K., McKibbin-Vaughan, T., Dornblaser, M.M., Hirschberg, D., Livingston, H.D., Buesseler, K.O., 1990. ${ }^{210} \mathrm{~Pb}$ scavenging in the North Atlantic and North Pacific Oceans. Earth Planet. Sci. Lett. 97, 332-352.

Crocket, K.C., Vance, D., Foster, G.L., Richards, D.A., Tranter, M., 2012. Continental weathering fluxes during the last glacial/interglacial cycle: insights from the marine sedimentary $\mathrm{Pb}$ isotope record at Orphan Knoll, NW Atlantic. Quat. Sci. Rev. 38, 89-99.

Dong, J.G., Wang, Y.J., Cheng, H., Hardt, B., Edwards, R.L., Kong, X.G., Wu, J.Y., Chen, S.T., Liu, D.B., Jiang, X.Y., Zhao, K., 2010. A high-resolution stalagmite record of the Holocene East Asian monsoon from Mt Shennongjia, central China. Holocene 20, 257-264.

Dupre, B., Dessert, C., Oliva, P., Godderis, Y., Viers, J., Francois, L., Millot, R., Gaillardet, J., 2003. Rivers, chemical weathering and Earth's climate. C. R. Geosci. 335, 1141-1160. 
Edmond, J.M., 1992. Himalayan tectonics, weathering processes and the strontium isotope record in marine limestones. Science 258, 1594-1597.

674 Erel, Y.G., Harlavan, Y., Blum, J.D., 1994. Lead isotope systematics of granitoid weathering.

675 Geochim. Cosmochim. Acta 58, 5299-5306.

676 Farrell, J.W., Janacek, T.R., 1991. Late Neogene paleoceanography and paleoclimatology of the 677 northeast Indian Ocean (site 758). Proceedings of the Ocean Drilling Program Scientific Results 121, $678 \quad 297-355$.

679 Foster, G.L., Vance, D., 2006. Negligible glacial-interglacial variation in continental chemical 680 weathering rates. Nature 444, 918-921.

681 Frank, M., 2002. Radiogenic isotopes: Tracers of past ocean circulation and erosional input. Rev. 682 Geophys. 40, doi: 10.1029/2000rg000094.

683 Frank, M., O'Nions, R.K., 1998. Sources of Pb for Indian ocean ferromanganese crusts: a record of 684 Himalayan erosion? Earth Planet. Sci. Lett. 158, 121-130.

685 Frank, M., Whiteley, N., van de Flierdt, T., Reynolds, B.C., O'Nions, K., 2006. Nd and Pb isotope evolution of deep water masses in the eastern Indian Ocean during the past $33 \mathrm{Myr}$. Chemical Geology 226, 264-279.

688 Galer, S.J.G., Abouchami, W., 1998. Practical application of lead triple spiking for correction of instrumental mass discrimination. Mineralogical Magazine 62A, 491-492.

690 Galy, A., France-Lanord, C., 1999. Weathering processes in the Ganges-Brahmaputra basin and the 691 riverine alkalinity budget. Chemical Geology 159, 31-60.

692 Galy, V., Eglinton, T., 2011. Protracted storage of biospheric carbon in the Ganges-Brahmaputra 693 basin. Nat. Geosci. 4, 843-847.

694 Galy, V., Francois, L., France-Lanord, C., Faure, P., Kudrass, H., Palhol, F., Singh, S.K., 2008. C4 695 plants decline in the Himalayan basin since the Last Glacial Maximum. Quat. Sci. Rev. 27, 13966961409.

697 Garcon, M., Chauvel, C., France-Lanord, C., Limonta, M., Garzanti, E., 2013. Removing the "heavy 698 mineral effect" to obtain a new Pb isotopic value for the upper crust. Geochem. Geophys. Geosyst. 14, 699 3324-3333.

Garcon, M., Chauvel, C., France-Lanord, C., Limonta, M., Garzanti, E., 2014. Which minerals control the Nd-Hf-Sr-Pb isotopic compositions of river sediments? Chemical Geology 364, 42-55.

Goldstein, S.L., Hemming, S.R., 2003. Long-lived isotopic tracers in oceanography, paleoceanography and ice sheet dynamics, in: Elderfield, H. (Ed.), The Oceans and Marine Geochemistry. Elsevier-

704 Pergamon, Oxford, pp. 453-489.

Goodbred, S.L., 2003. Response of the Ganges dispersal system to climate change: a source-to-sink view since the last interstade. Sediment. Geol. 162, 83-104. 
Gutjahr, M., Frank, M., Halliday, A.N., Keigwin, L.D., 2009. Retreat of the Laurentide ice sheet tracked by the isotopic composition of $\mathrm{Pb}$ in western North Atlantic seawater during termination 1. Earth Planet. Sci. Lett. 286, 546-555.

713

714

715

716

717

718

Gutjahr, M., Frank, M., Stirling, C.H., Klemm, V., van de Flierdt, T., Halliday, A.N., 2007. Reliable extraction of a deepwater trace metal isotope signal from $\mathrm{Fe}-\mathrm{Mn}$ oxyhydroxide coatings of marine sediments. Chemical Geology 242, 351-370.

Haley, B.A., Frank, M., Spielhagen, R.F., Fietzke, J., 2008. Radiogenic isotope record of Arctic Ocean circulation and weathering inputs of the past 15 million years. Paleoceanography 23, doi: $10.1029 / 2007 \mathrm{pa} 001486$.

Harlavan, Y., Erel, Y., 2002. The release of $\mathrm{Pb}$ and REE from granitoids by the dissolution of accessory phases. Geochim. Cosmochim. Acta 66, 837-848.

Henderson, G.M., Maier-Reimer, E., 2002. Advection and removal of ${ }^{210} \mathrm{~Pb}$ and stable $\mathrm{Pb}$ isotopes in the oceans: A general circulation model study. Geochim. Cosmochim. Acta 66, 257-272.

Hirata, T., 1996. Lead isotopic analyses of NIST standard reference materials using multiple collector inductively coupled plasma mass spectrometry coupled with a modified external correction method for mass discrimination effect. Analyst 121, 1407-1411.

Iwamori, H., Albarede, F., Nakamura, H., 2010. Global structure of mantle isotopic heterogeneity and its implications for mantle differentiation and convection. Earth Planet. Sci. Lett. 299, 339-351.

Jones, C.E., Halliday, A.N., Rea, D.K., Owen, R.M., 2000. Eolian inputs of lead to the North Pacific. Geochim. Cosmochim. Acta 64, 1405-1416.

Klemm, V., Reynolds, B., Frank, M., Pettke, T., Halliday, A.N., 2007. Cenozoic changes in atmospheric lead recorded in central Pacific ferromanganese crusts. Earth Planet. Sci. Lett. 253, 57-66.

Kudrass, H.R., Hofmann, A., Doose, H., Emeis, K., Erlenkeuser, H., 2001. Modulation and amplification of climatic changes in the Northern Hemisphere by the Indian summer monsoon during the past 80 k.y. Geology 29, 63-66.

Lacan, F., Jeandel, C., 2005. Neodymium isotopes as a new tool for quantifying exchange fluxes at the continent-ocean interface. Earth Planet. Sci. Lett. 232, 245-257.

Ling, H.F., Jiang, S.Y., Frank, M., Zhou, H.Y., Zhou, F., Lu, Z.L., Chen, X.M., Jiang, Y.H., Ge, C.D., 2005. Differing controls over the Cenozoic $\mathrm{Pb}$ and $\mathrm{Nd}$ isotope evolution of deepwater in the central North Pacific Ocean. Earth Planet. Sci. Lett. 232, 345-361.

Lisiecki, L.E., Raymo, M.E., 2005. A Pliocene-Pleistocene stack of 57 globally distributed benthic $\delta^{18}$ O records. Paleoceanography 20, doi: $10.1029 / 2004$ pa001071.

Lupker, M., Blard, P.H., Lave, J., France-Lanord, C., Leanni, L., Puchol, N., Charreau, J., Bourles, D., 2012. ${ }^{10}$ Be-derived Himalayan denudation rates and sediment budgets in the Ganga basin. Earth Planet. Sci. Lett. 333, 146-156.

Lupker, M., France-Lanord, C., Galy, V., Lave, J., Kudrass, H., 2013. Increasing chemical weathering in the Himalayan system since the Last Glacial Maximum. Earth Planet. Sci. Lett. 365, 243-252.

Mahowald, N.M., Muhs, D.R., Levis, S., Rasch, P.J., Yoshioka, M., Zender, C.S., Luo, C., 2006. Change in atmospheric mineral aerosols in response to climate: Last glacial period, preindustrial, modern, and doubled carbon dioxide climates. J. Geophys. Res.-Atmos. 111, doi: 10.1029/2005jd006653. 
Mantyla, A.W., Reid, J.L., 1995. On the origins of deep and bottom waters of the Indian Ocean. J. Geophys. Res.-Oceans 100, 2417-2439.

753

754

755

756

757

758

759

760

761

762

763

764

765

766

767

768

769

770

771

772

773

774

775

776

777

McCave, I.N., Kiefer, T., Thornalley, D.J.R., Elderfield, H., 2005. Deep flow in the MadagascarMascarene Basin over the last 150000 years. Philosophical Transactions of the Royal Society of London Series a-Mathematical Physical and Engineering Sciences 363, 81-99.

Milliman, J.D., Farnsworth, K.L., 2013. River discharge to the coastal ocean: a global synthesis. Cambridge University Press.

Millot, R., Allegre, C.J., Gaillardet, J., Roy, S., 2004. Lead isotopic systematics of major river sediments: a new estimate of the Pb isotopic composition of the Upper Continental Crust. Chemical Geology 203, 75-90.

Misra, S., Froelich, P.N., 2012. Lithium isotope history of Cenozoic seawater: changes in silicate weathering and reverse weathering. Science 335, 818-823.

Nielsen, S.G., Gannoun, A., Marnham, C., Burton, K.W., Halliday, A.N., Hein, J.R., 2011. New age for ferromanganese crust 109D-C and implications for isotopic records of lead, neodymium, hafnium, and thallium in the Pliocene Indian Ocean. Paleoceanography 26, doi: 10.1029/2010pa002003.

Nishioka, J., Obata, H., Tsumune, D., 2013. Evidence of an extensive spread of hydrothermal dissolved iron in the Indian Ocean. Earth Planet. Sci. Lett. 361, 26-33.

Pattan, J.N., Pearce, N.J.G., 2009. Bottom water oxygenation history in southeastern Arabian Sea during the past $140 \mathrm{ka}$ : Results from redox-sensitive elements. Paleogeogr. Paleoclimatol. Paleoecol. 280, 396-405.

Pausata, F.S.R., Battisti, D.S., Nisancioglu, K.H., Bitz, C.M., 2011. Chinese stalagmite $\delta^{18} O$ controlled by changes in the Indian monsoon during a simulated Heinrich event. Nat. Geosci. 4, 474480 .

Pearce, C.R., Jones, M.T., Oelkers, E.H., Pradoux, C., Jeandel, C., 2013. The effect of particulate dissolution on the neodymium (Nd) isotope and Rare Earth Element (REE) composition of seawater. Earth Planet. Sci. Lett. 369, 138-147.

Piotrowski, A.M., Banakar, V.K., Scrivner, A.E., Elderfield, H., Galy, A., Dennis, A., 2009. Indian Ocean circulation and productivity during the last glacial cycle. Earth Planet. Sci. Lett. 285, 179-189.

Punyu, V.R., Banakar, V.K., Garg, A., 2014. Equatorial Indian Ocean productivity during the last 33 kyr and possible linkage to Westerly Jet variability. Mar. Geol. 348, 44-51.

Raymo, M.E., Ruddiman, W.F., Froelich, P.N., 1988. Influence of late Cenozoic mountain building on ocean geochemical cycles. Geology 16, 649-653.

Rehkamper, M., Mezger, K., 2000. Investigation of matrix effects for $\mathrm{Pb}$ isotope ratio measurements by multiple collector ICP-MS: verification and application of optimized analytical protocols. J. Anal. At. Spectrom. 15, 1451-1460.

Reynolds, B.C., Sherlock, S.C., Kelley, S.P., Burton, K.W., 2004. Radiogenic isotope records of Quaternary glaciations: Changes in the erosional source and weathering processes. Geology 32, 861864.

Richter, F.M., Rowley, D.B., DePaolo, D.J., 1992. Sr isotope evolution of seawater: the role of tectonics. Earth Planet. Sci. Lett. 109, 11-23. 
Richter, F.M., Turekian, K.K., 1993. Simple models for the geochemical response of the ocean to climatic and tectonic forcing. Earth Planet. Sci. Lett. 119, 121-131.

793

794

795

796

797

798

799

800

801

802

803

804

805

806

807

808

809

810

811

812

813

814

815

816

817

818

819

820

821

822

823

824

825

826

827

828

829

Riebe, C.S., Kirchner, J.W., Finkel, R.C., 2004. Erosional and climatic effects on long-term chemical weathering rates in granitic landscapes spanning diverse climate regimes. Earth Planet. Sci. Lett. 224, 547-562.

Riebe, C.S., Kirchner, J.W., Granger, D.E., Finkel, R.C., 2001. Strong tectonic and weak climatic control of long-term chemical weathering rates. Geology 29, 511-514.

Rostek, F., Bard, E., Beaufort, L., Sonzogni, C., Ganssen, G., 1997. Sea surface temperature and productivity records for the past $240 \mathrm{kyr}$ in the Arabian Sea. Deep-Sea Res. Part II-Top. Stud. Oceanogr. 44, 1461-1480.

Schaule, B.K., Patterson, C.C., 1981. Lead concentrations in the northeast Pacific: evidence for global anthropogenic perturbations. Earth Planet. Sci. Lett. 54, 97-116.

Siddall, M., Khatiwala, S., van de Flierdt, T., Jones, K., Goldstein, S.L., Hemming, S., Anderson, R.F., 2008. Towards explaining the Nd paradox using reversible scavenging in an ocean general circulation model. Earth Planet. Sci. Lett. 274, 448-461.

Stacey, J.S., Delevaux, M.E., Ulrych, T.J., 1969. Some triple-filament lead isotope ratio measurements and an absolute growth curve for single-stage leads. Earth Planet. Sci. Lett. 6, 15-25.

Stoll, H.M., Vance, D., Arevalos, A., 2007. Records of the Nd isotope composition of seawater from the Bay of Bengal: Implications for the impact of Northern Hemisphere cooling on ITCZ movement. Earth Planet. Sci. Lett. 255, 213-228.

Stumpf, R., Frank, M., Schonfeld, J., Haley, B.A., 2010. Late Quaternary variability of Mediterranean Outflow Water from radiogenic Nd and Pb isotopes. Quat. Sci. Rev. 29, 2462-2472.

Tachikawa, K., Toyofuku, T., Basile-Doelsch, I., Delhaye, T., 2013. Microscale neodymium distribution in sedimentary planktonic foraminiferal tests and associated mineral phases. Geochim. Cosmochim. Acta 100, 11-23.

Thomas, A.L., Henderson, G.M., McCave, I.N., 2007. Constant bottom water flow into the Indian Ocean for the past $140 \mathrm{ka}$ indicated by sediment ${ }^{231} \mathrm{~Pa} /{ }^{230} \mathrm{Th}$ ratios. Paleoceanography 22, doi: 10.1029/2007PA001415.

van de Flierdt, T., Frank, M., Lee, D.C., Halliday, A.N., 2002. Glacial weathering and the hafnium isotope composition of seawater. Earth Planet. Sci. Lett. 198, 167-175.

Vlastelic, I., Abouchami, W., Galer, S.J.G., Hofmann, A.W., 2001. Geographic control on Pb isotope distribution and sources in Indian Ocean Fe-Mn deposits. Geochim. Cosmochim. Acta 65, 4303-4319.

von Blanckenburg, F., 1999. Perspectives: Paleoceanography - Tracing past ocean circulation? Science 286, 1862-1863.

von Blanckenburg, F., Nagler, T.F., 2001. Weathering versus circulation-controlled changes in radiogenic isotope tracer composition of the Labrador Sea and North Atlantic Deep Water. Paleoceanography 16, 424-434.

von Blanckenburg, F., O'Nions, R.K., Hein, J.R., 1996. Distribution and sources of pre-anthropogenic lead isotopes in deep ocean water from Fe-Mn crusts. Geochim. Cosmochim. Acta 60, 4957-4963. 
830 Wang, Y.J., Cheng, H., Edwards, R.L., An, Z.S., Wu, J.Y., Shen, C.C., Dorale, J.A., 2001. A high831 resolution absolute-dated Late Pleistocene monsoon record from Hulu Cave, China. Science 294, $832 \quad 2345-2348$.

833 Wang, Y.J., Cheng, H., Edwards, R.L., Kong, X.G., Shao, X.H., Chen, S.T., Wu, J.Y., Jiang, X.Y., 834 Wang, X.F., An, Z.S., 2008. Millennial- and orbital-scale changes in the East Asian monsoon over the 835 past 224,000 years. Nature 451, 1090-1093.

836 West, A.J., Galy, A., Bickle, M., 2005. Tectonic and climatic controls on silicate weathering. Earth 837 Planet. Sci. Lett. 235, 211-228.

838 White, A.F., Blum, A.E., 1995. Effects of continental climate on chemical weathering in watersheds. 839 Geochim. Cosmochim. Acta 59, 1729-1747.

840 Wilson, D.J., Piotrowski, A.M., Galy, A., Clegg, J.A., 2013. Reactivity of neodymium carriers in deep 841 sea sediments: Implications for boundary exchange and paleoceanography. Geochim. Cosmochim. 842 Acta 109, 197-221.

843 Wilson, D.J., Piotrowski, A.M., Galy, A., McCave, I.N., 2012. A boundary exchange influence on 844 deglacial neodymium isotope records from the deep western Indian Ocean. Earth Planet. Sci. Lett. $845 \quad 341,35-47$.

846 You, Y., 2000. Implications of the deep circulation and ventilation of the Indian Ocean on the renewal 847 mechanism of North Atlantic Deep Water. J. Geophys. Res.-Oceans 105, 23895-23926. 


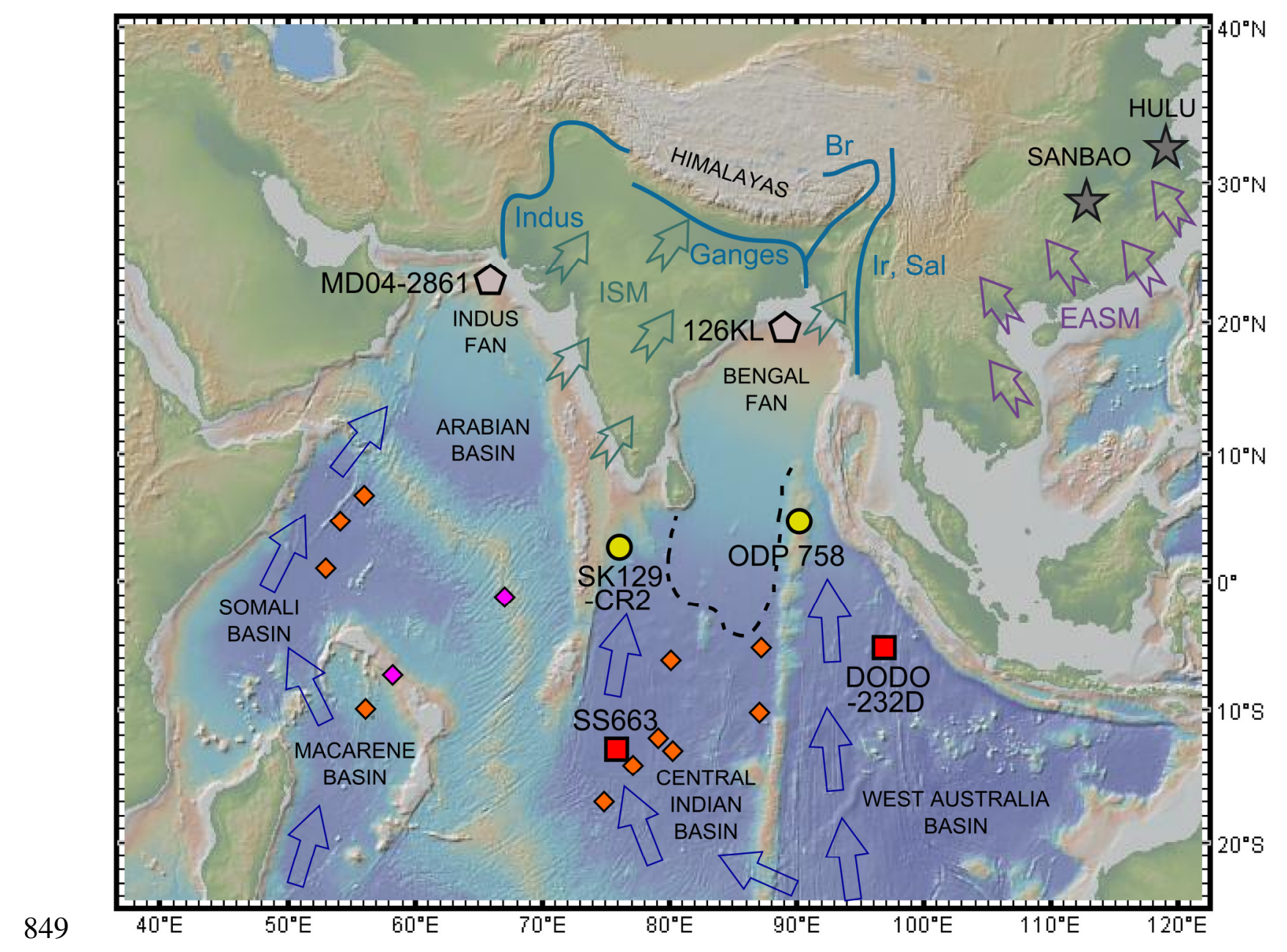

851 Figure 1: Location map for studied cores SK129-CR2 $\left(3^{\circ} \mathrm{N}, 76^{\circ} \mathrm{E}, 3800 \mathrm{~m}\right.$ depth) and ODP $758\left(5^{\circ} \mathrm{N}\right.$, $85290^{\circ} \mathrm{E}, 2925 \mathrm{~m}$ depth) (yellow circles). Ferromanganese crusts with existing $\mathrm{Pb}$ isotope records are 853 SS663 (Frank and O'Nions, 1998) and DODO-232D (Frank et al., 2006) (red squares).

854 Ferromanganese crusts and nodules whose surface layers were analysed for $\mathrm{Pb}$ isotopes are also 855 plotted (von Blanckenburg et al., 1996, pink diamonds; Vlastelic et al., 2001, orange diamonds, their 856 N-Indian domain). Blue arrows show schematic representation of the deep circulation (after Mantyla 857 and Reid, 1995; You, 2000) and dotted line shows the extent of the Bengal Fan. Also shown are 858 sediment cores SO93-126KL (Kudrass et al., 2001) and MD04-2861 (Caley et al., 2011) (grey 859 pentagons); Chinese speleothems from Sanbao and Hulu caves (Wang et al., 2001; Wang et al., 2008; 860 Cheng et al., 2009) (grey stars); major rivers (Br=Brahmaputra, Ir=Irrawaddy, Sal=Salween) and 861 schematic representation of Indian Summer Monsoon (ISM) and East Asian Summer Monsoon 862 (EASM) (green and purple arrows). 

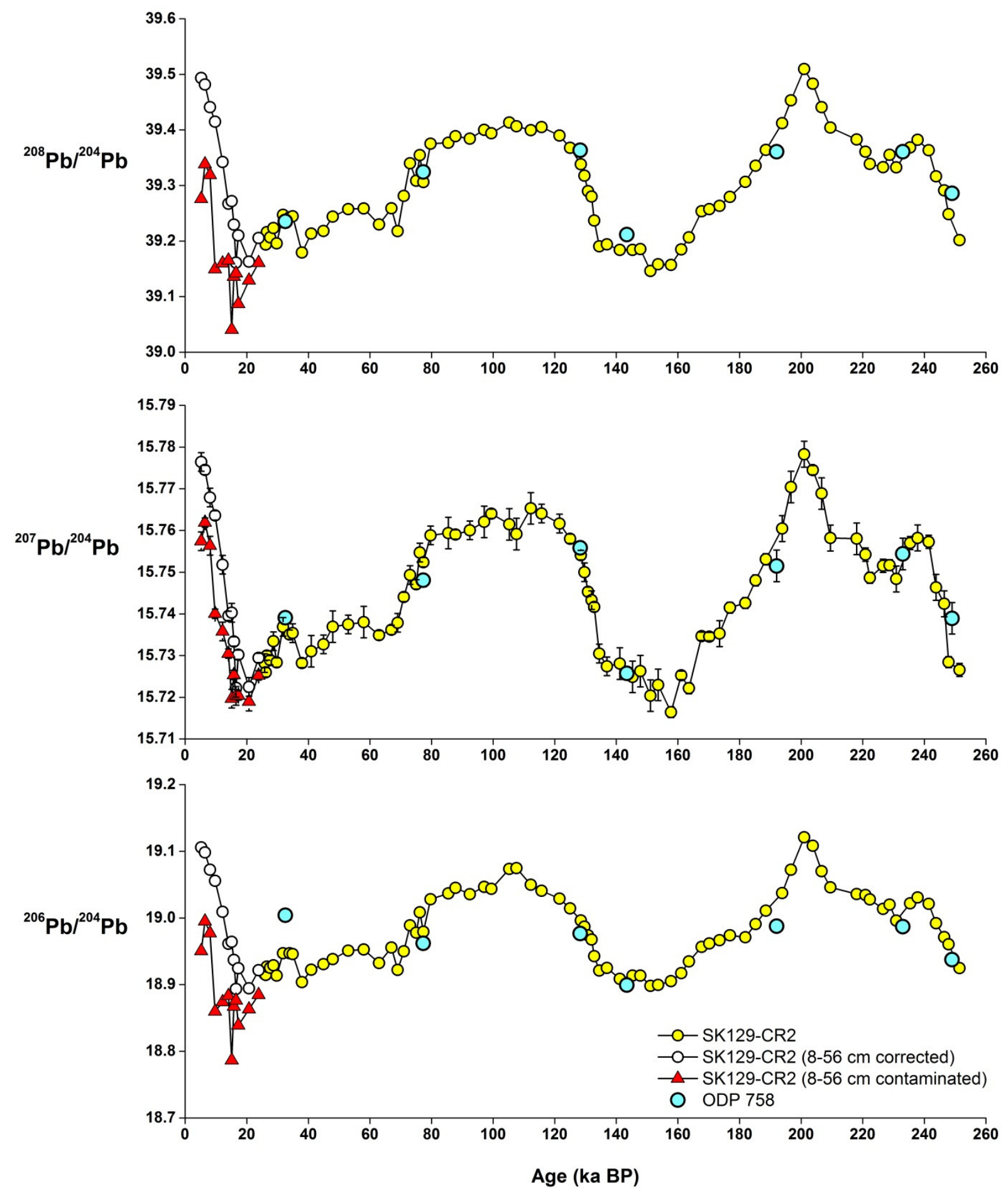

Figure 2: Sediment leachate $\mathrm{Pb}$ isotope data from $\mathrm{SK} 129-\mathrm{CR} 2$ plotted on an age scale and compared to sediment leachate data from ODP 758. Panels show ${ }^{208} \mathrm{~Pb} /{ }^{204} \mathrm{~Pb},{ }^{207} \mathrm{~Pb} /{ }^{204} \mathrm{~Pb}$ and ${ }^{206} \mathrm{~Pb} /{ }^{204} \mathrm{~Pb}$ records. Both measured data and anthropogenic-corrected data are plotted for the 8-56 cm section of SK129CR2 (see Supplementary Information for full details). Measurement uncertainty is shown with error bars for ${ }^{207} \mathrm{~Pb} /{ }^{204} \mathrm{~Pb}$ and is comparable to or smaller than symbol sizes for ${ }^{206} \mathrm{~Pb} /{ }^{204} \mathrm{~Pb}$ and ${ }^{208} \mathrm{~Pb} /{ }^{204} \mathrm{~Pb}$. 

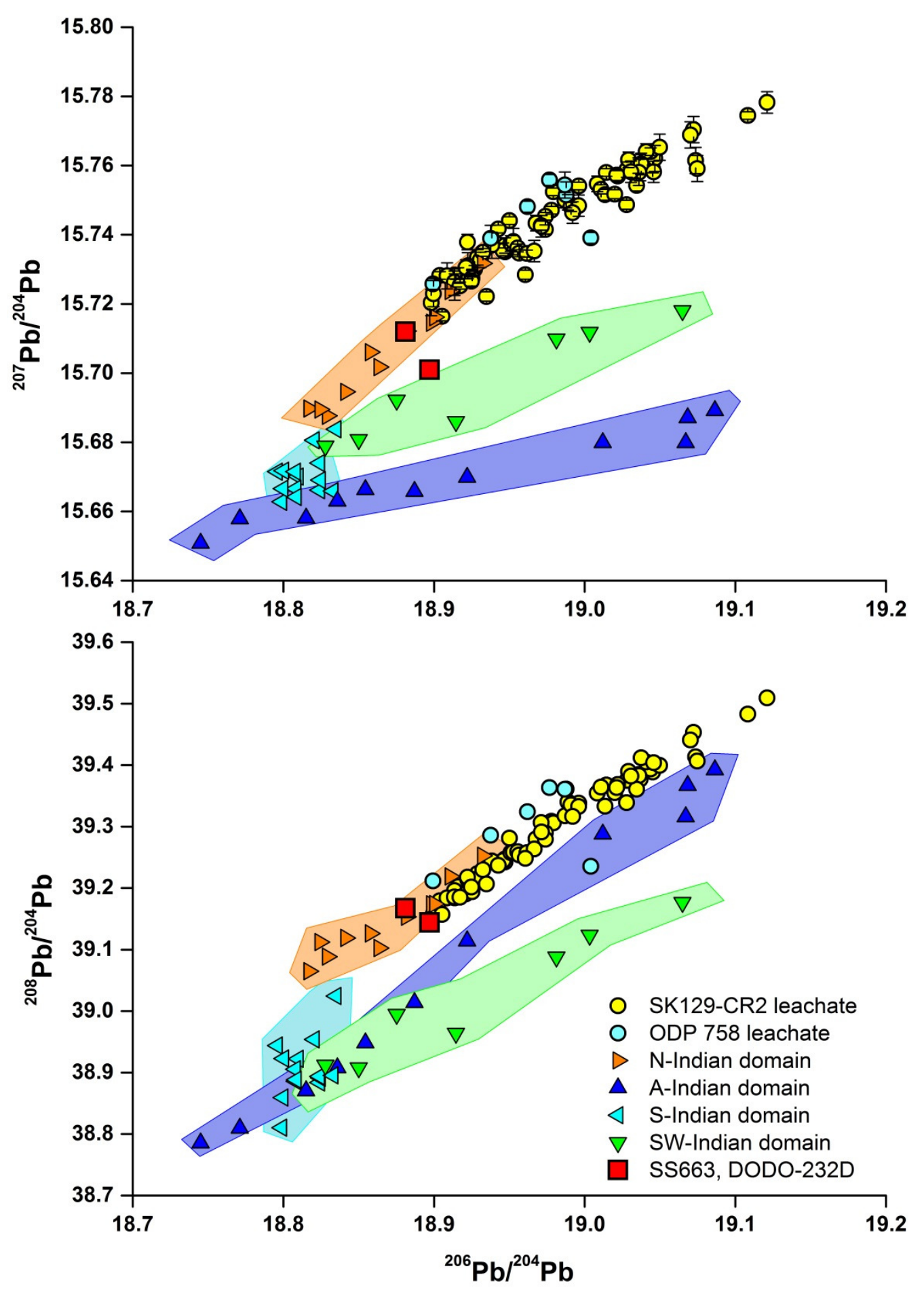

874 Figure 3: Sediment leachate $\mathrm{Pb}$ isotope data from $\mathrm{SK} 129-\mathrm{CR} 2$ and ODP 758 plotted as $\mathrm{Pb}-\mathrm{Pb}$ plots $\left({ }^{207} \mathrm{~Pb} /{ }^{204} \mathrm{~Pb}\right.$ versus ${ }^{206} \mathrm{~Pb} /{ }^{204} \mathrm{~Pb},{ }^{208} \mathrm{~Pb} /{ }^{204} \mathrm{~Pb}$ versus $\left.{ }^{206} \mathrm{~Pb} /{ }^{204} \mathrm{~Pb}\right)$ and compared to data from Indian Ocean ferromanganese crusts (Frank and O'Nions, 1998; Vlastelic et al., 2001; Frank et al., 2006). Samples from the N-Indian domain of Vlastelic et al. (2001) are located on Figure 1, while the other domains of that study represent other regions of the Indian Ocean (N, North; A, Antarctic; S, South; SW, Southwest; see Figure 5 of Vlastelic et al., 2001). The SK129-CR2 data are in good agreement with the N-Indian array (Vlastelic et al., 2001), with the surface layers of ferromanganese crusts SS663 and DODO-232D (Frank and O'Nions, 1998; Frank et al., 2006), and with data from two ferromanganese crusts studied by von Blanckenburg et al. (1996) (Figure 1) which are not plotted here due to their significantly larger measurement uncertainties. Measurement uncertainty is shown with error bars for ${ }^{207} \mathrm{~Pb} /{ }^{204} \mathrm{~Pb}$ and is comparable to or smaller than symbol sizes for ${ }^{206} \mathrm{~Pb} /{ }^{204} \mathrm{~Pb}$ and ${ }^{208} \mathrm{~Pb} /{ }^{204} \mathrm{~Pb}$. 


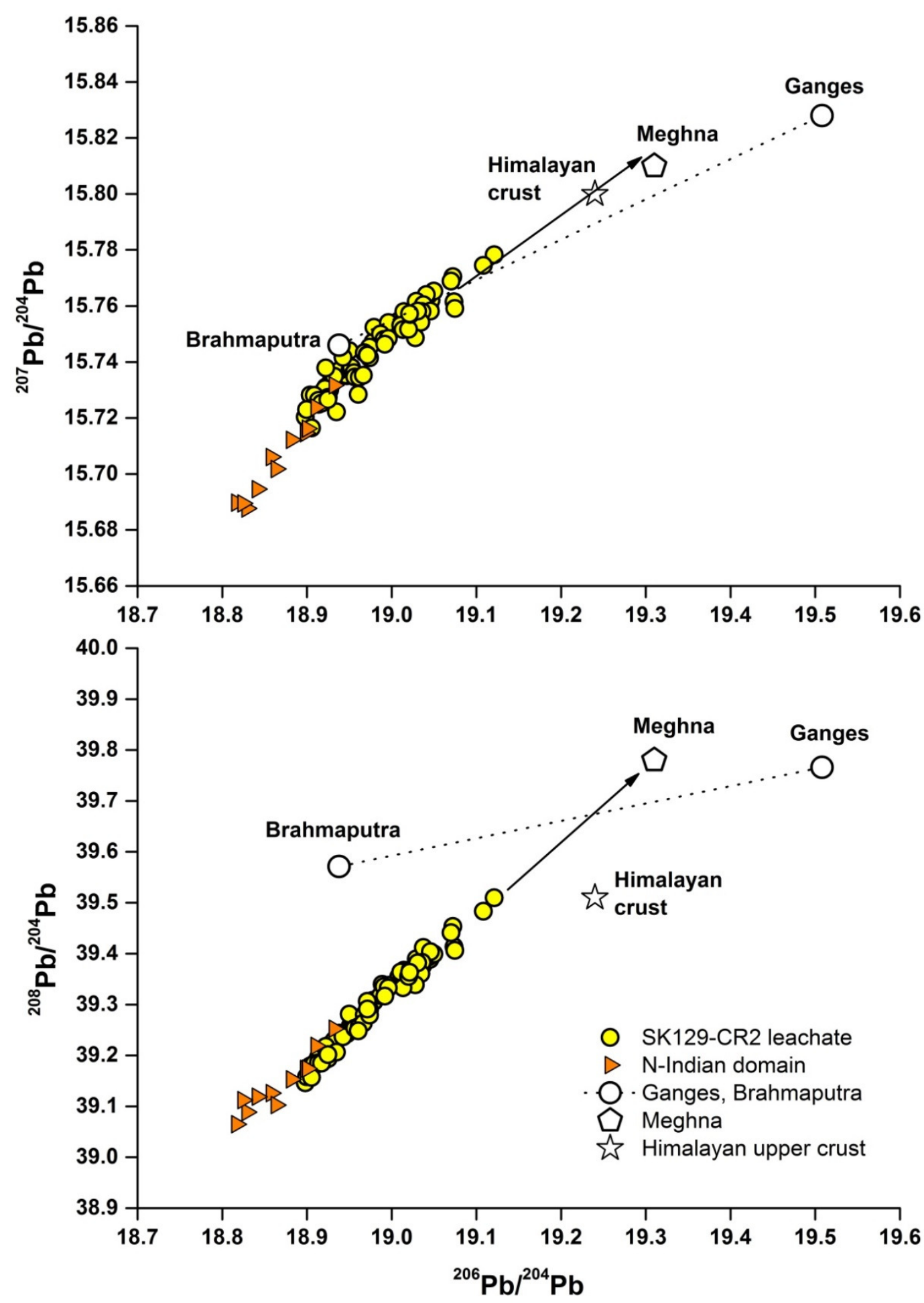

Figure 4: $\mathrm{Pb}-\mathrm{Pb}$ plots assessing the radiogenic $\mathrm{Pb}$ endmember for SK129-CR2 and the $\mathrm{N}$-Indian domain. Filled symbols show authigenic data and open symbols show detrital data. Ferromanganese nodule data are from Vlastelic et al. (2001). Ganges and Brahmaputra suspended sediment data are

891 from Millot et al. (2004). Lower Meghna suspended sediment data are from this study. The estimate of

892 Himalayan upper crust composition is from Garcon et al. (2013). Dotted lines indicate the theoretical mixing line between Ganges and Brahmaputra sediment, but note that measured data from the Lower Meghna plot above this line. Arrows indicate the approximate mixing between the SK129-CR2 array and the Lower Meghna composition. Measurement uncertainty is comparable to or smaller than symbol sizes. 

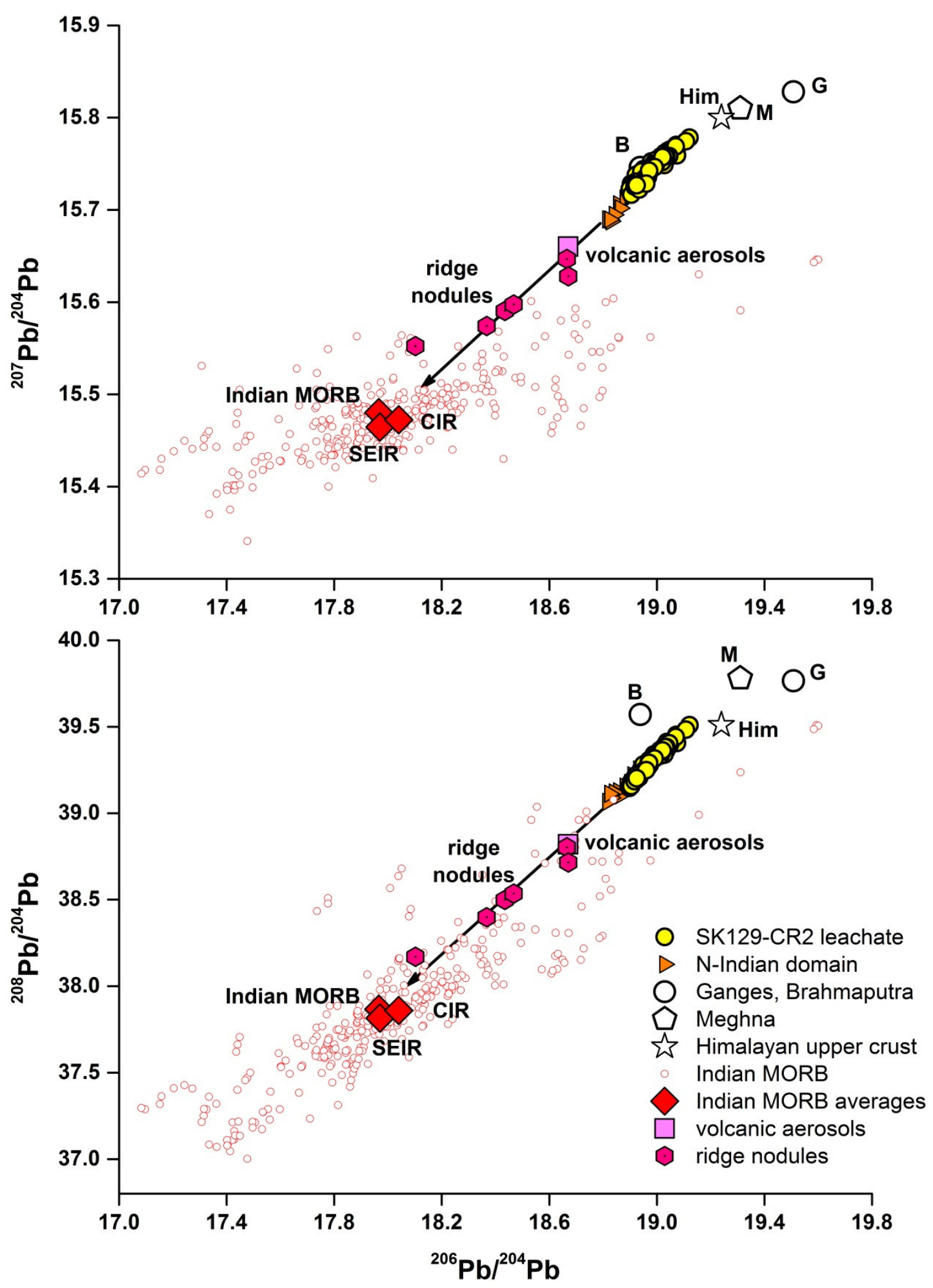

Figure 5: $\mathrm{Pb}-\mathrm{Pb}$ plots assessing the unradiogenic $\mathrm{Pb}$ endmember for SK129-CR2 and the N-Indian domain. Indian MORB data (Iwamori et al., 2010) are plotted from $30-130^{\circ} \mathrm{E}$, together with their mean value, and the mean values for the Southeast Indian Ridge $120-125^{\circ} \mathrm{E}$ (SEIR) and Central Indian Ridge $10^{\circ} \mathrm{N}-25^{\circ} \mathrm{S}$ (CIR). Arrows indicate the approximate mixing between those mean values and the SK129-CR2 array. Also shown are the compositions of ferromanganese nodules from Indian ridges (Vlastelic et al., 2001) and the composition of a globally well-mixed volcanic aerosol source inferred from the leachable component of Chinese loess (Jones et al., 2000). Other data references are 


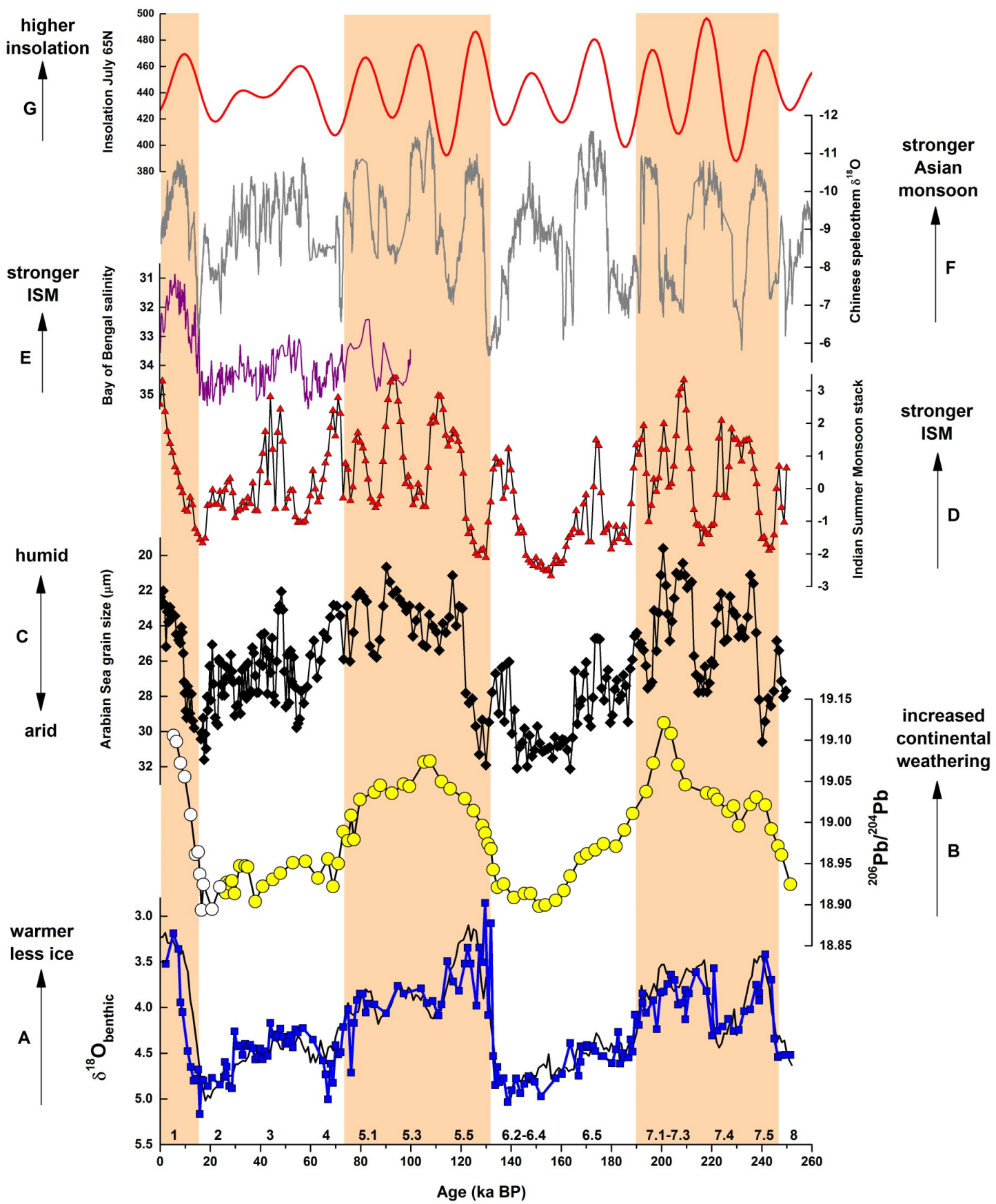

Figure 6: SK129-CR2 Pb isotope record compared to global and regional climate records. (A) SK129$\mathrm{CR} 2$ benthic $\delta^{18} \mathrm{O}$ (blue squares) corrected to equilibrium values (+0.64) and compared to the LR04 benthic $\delta^{18} \mathrm{O}$ stack (black line) (Lisiecki and Raymo, 2005). Numbers along the $\mathrm{x}$ axis are MIS numbers. (B) SK129-CR2 leachate ${ }^{206} \mathrm{~Pb} /{ }^{204} \mathrm{~Pb}$ (yellow circles for measured data, white circles for anthropogenic-corrected data for Termination I). (C) Reconstruction of continental aridity based on grain size of the silt fraction in Arabian Sea core MD04-2861 (Caley et al., 2011; see Figure 1 for location). (D) Indian Summer Monsoon stack from Arabian Sea core MD04-2861 (Caley et al., 2011). (E) Bay of Bengal salinity reconstructed from planktonic oxygen isotopes in core SO93-126KL (Kudrass et al., 2001; see Figure 1 for location). (F) Chinese speleothem $\delta^{18} \mathrm{O}$ compilation from Hulu and Sanbao Caves (Wang et al., 2001; Wang et al., 2008; Cheng et al., 2009; see Figure 1 for locations), with Hulu cave data adjusted by $-1.6 \%$ o to account for their offset from Sanbao. (G) July insolation at $65^{\circ} \mathrm{N}$ (Berger and Loutre, 1991). Note that the records in (C-F) are plotted on their original published age scales. ISM = Indian Summer Monsoon. 


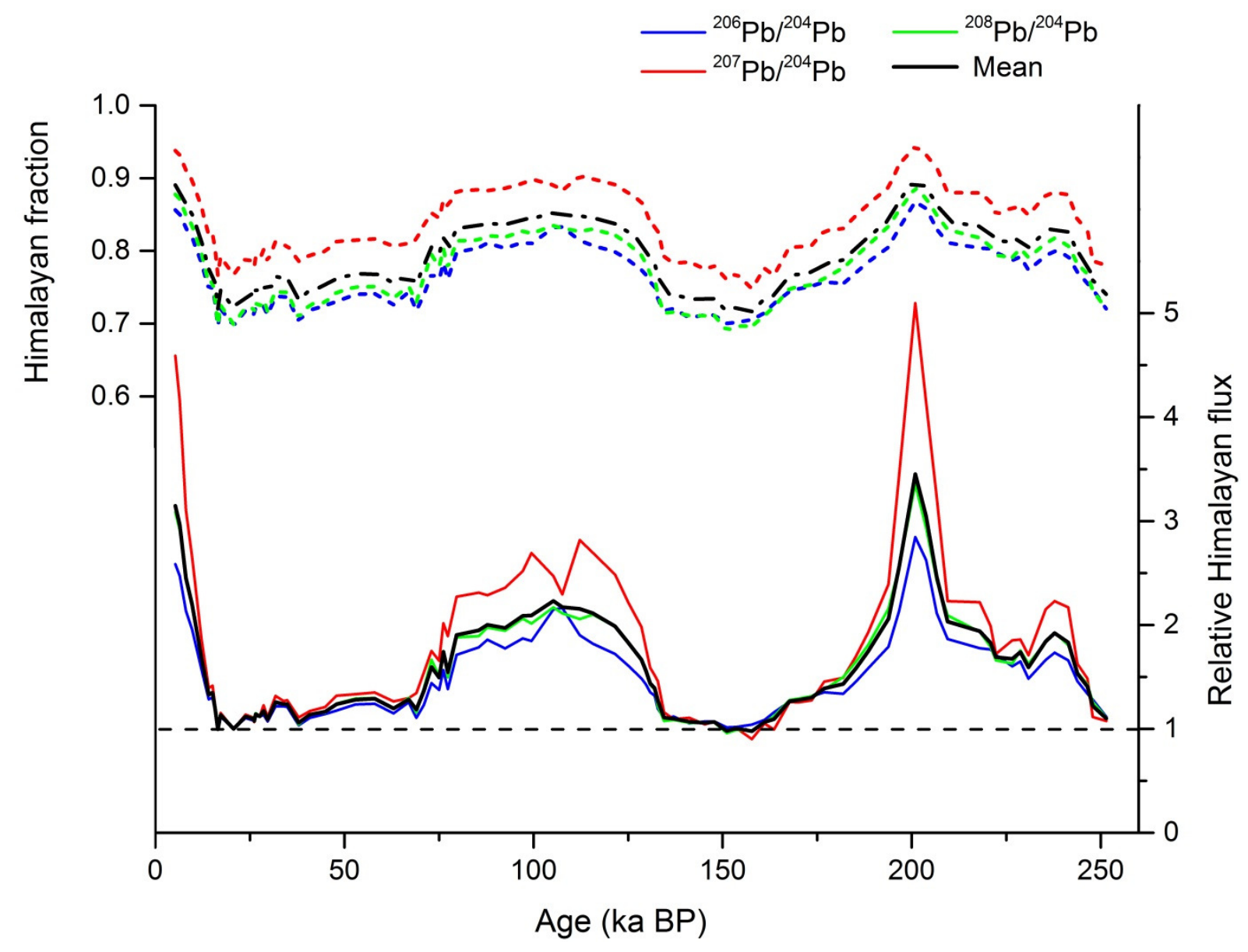

Figure 7: Constraints on the Himalayan $\mathrm{Pb}$ flux to SK129-CR2 based on $\mathrm{Pb}$ isotope mass balance calculations. The upper plot (dotted lines) shows the fraction of Himalayan Pb at SK129-CR2, based on mixing between mean Indian MORB $\left({ }^{206} \mathrm{~Pb} /{ }^{204} \mathrm{~Pb}=17.9663,{ }^{207} \mathrm{~Pb} /{ }^{204} \mathrm{~Pb}=15.4801,{ }^{208} \mathrm{~Pb} /{ }^{204} \mathrm{~Pb}=\right.$ 37.8670; Figure 5) and the Lower Meghna riverine composition (Figure 4). The lower plot (solid lines) converts this fraction into a Himalayan flux relative to the Last Glacial Maximum ( 21 ka BP), based on the assumption of a constant volcanic flux. The calculations are carried out separately for each of the three $\mathrm{Pb}$ isotope ratios, while the black line is based on the mean Himalayan fraction from the three calculations. 

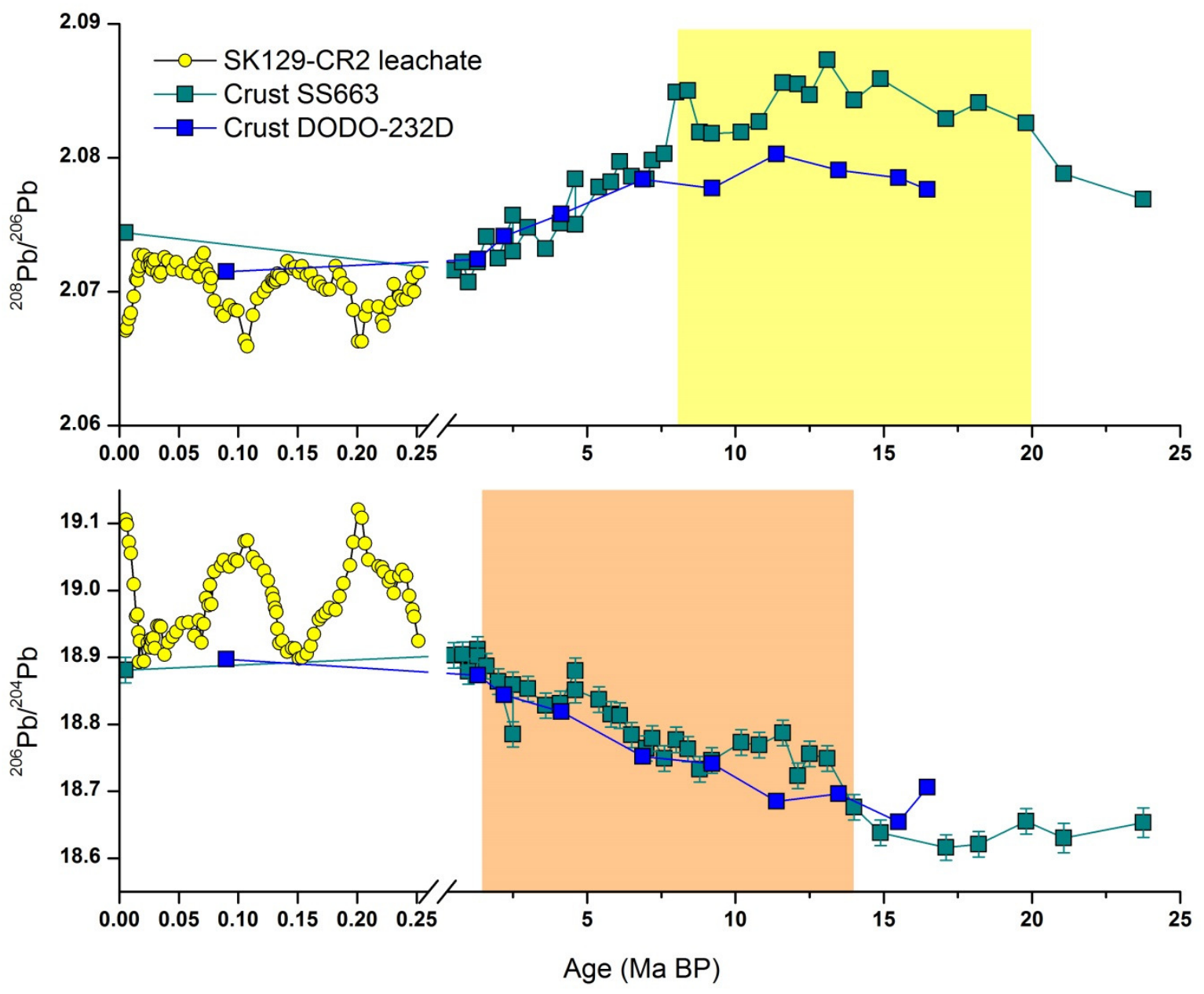

Figure 8: Time series evolution of deep central Indian $\mathrm{Ocean} \mathrm{Pb}$ isotopic composition reconstructed from sediment leachates in core SK129-CR2 (this study) and ferromanganese crusts SS663 (Frank and O'Nions, 1998) and DODO-232D (Frank et al., 2006) (see Figure 1 for crust locations). Crust ages are based on the original published age models. Note the break in the age axis at $0.25 \mathrm{Ma}$. The yellow band on the ${ }^{208} \mathrm{~Pb} /{ }^{206} \mathrm{~Pb}$ plot highlights the period with elevated ${ }^{208} \mathrm{~Pb} /{ }^{206} \mathrm{~Pb}$ ratios which was originally attributed to increased Himalayan inputs during this period (Frank and O'Nions, 1998). The orange bar on the ${ }^{206} \mathrm{~Pb} /{ }^{204} \mathrm{~Pb}$ plot highlights the period during which we now infer increasing Himalayan contributions in those crusts. Error bars are only shown where these are larger than the symbols, with the exception of the ${ }^{208} \mathrm{~Pb} /{ }^{206} \mathrm{~Pb}$ data for SS663 for which uncertainties were not reported. 


\section{SUPPLEMENTARY INFORMATION}

"Quaternary climate modulation of Pb isotopes in the deep Indian Ocean linked to the Himalayan chemical weathering” by Wilson D.J., Galy A., Piotrowski A.M., and Banakar V.K.

\section{Age model}

The age model for SK129-CR2 is constrained by planktonic radiocarbon dates for 033 ka BP (Table S1), beyond which the benthic foraminiferal C. wuellerstorfi $\delta^{18} \mathrm{O}$ record (Table S2) is tuned to the LR04 benthic $\delta^{18} \mathrm{O}$ stack (Lisiecki and Raymo, 2005) at major marine isotope stage (MIS) boundaries. Linear interpolation was used between all radiocarbon and benthic $\delta^{18} \mathrm{O}$ tie points. The depth-age tie points and linear sedimentation rates are detailed in Table S3. We note that the LR04 record has an absolute age uncertainty of $\sim 4$ kyr over this time period (Lisiecki and Raymo, 2005).

\section{Chemical purification and mass spectrometry - complete method details}

The $\mathrm{Pb}$ fraction was separated using BioRad AG1-X8 anion exchange resin (100-200 $\mu \mathrm{m}$ mesh) in $100 \mu \mathrm{l}$ Teflon columns in laminar flow hoods using quartz-distilled acids. The columns were washed with $6 \mathrm{M} \mathrm{HCl}$ and primed with $0.7 \mathrm{M} \mathrm{HBr}$ before samples were loaded in $0.7 \mathrm{M} \mathrm{HBr}$. After washing with $0.7 \mathrm{M} \mathrm{HBr}$ and $2 \mathrm{M} \mathrm{HCl}$, the $\mathrm{Pb}$ was eluted in $6 \mathrm{M} \mathrm{HCl}$ and dried down, before being taken up in $2 \% \mathrm{HNO}_{3}$ for analysis by mass spectrometry.

The $\mathrm{Pb}$ isotopic composition was analysed on a $\mathrm{Nu}$ Plasma multi-collector inductively-coupled plasma mass spectrometer (MC-ICP-MS) in the Department of Earth Sciences at the University of Cambridge. Thallium (Tl) was used as an internal standard to correct for mass fractionation (Hirata, 1996; Belshaw et al., 1998) according to an exponential law. The reliability of this approach was optimised by using matrix- and concentration-matched standards and samples (Rehkamper and Mezger, 2000), spiking with a constant $\mathrm{Pb} / \mathrm{Tl}$ ratio $(\sim 2)$ and mixing $\mathrm{Pb}$ and $\mathrm{Tl}$ immediately prior to analysis (Kamenov et al., 2004). The mercury ( $\mathrm{Hg}$ ) beam was also monitored at mass 202 , allowing for an interference correction for the ${ }^{204} \mathrm{Hg}$ on ${ }^{204} \mathrm{~Pb}$ using the natural ${ }^{204} \mathrm{Hg} /{ }^{202} \mathrm{Hg}$ ratio, itself corrected for mass fractionation assessed by $\mathrm{Tl}$ and using an exponential law.

Concentration-matched NIST-SRM-981 $\mathrm{Pb}$ standards were measured after approximately every five samples, and a linear correction was applied to all data measured in each analytical session in order to produce agreement with the accepted composition of NIST-SRM-981 Pb (Galer and Abouchami, 1998; Abouchami et al., 2000). The standard deviation $(2 \sigma)$ of repeat measurements of NIST-SRM-981 measured and Tl-corrected as a sample provides our external reproducibility for samples analysed during each analytical 
session, giving reproducibility in the range of $30-180 \mathrm{ppm}$ for ${ }^{206} \mathrm{~Pb} /{ }^{204} \mathrm{~Pb}, 60-240 \mathrm{ppm}$ for ${ }^{207} \mathrm{~Pb} /{ }^{204} \mathrm{~Pb}$ and $50-250 \mathrm{ppm}$ for ${ }^{208} \mathrm{~Pb} /{ }^{204} \mathrm{~Pb}$. Two internal standards (leachate samples that had been through column chemistry) were also analysed in multiple analytical sessions over three years $(n=14-15)$ and yield typical long term reproducibility $(2 \sigma)$ of $140 \mathrm{ppm}$ for ${ }^{206} \mathrm{~Pb} /{ }^{204} \mathrm{~Pb}, 160 \mathrm{ppm}$ for ${ }^{207} \mathrm{~Pb} /{ }^{204} \mathrm{~Pb}$ and $190 \mathrm{ppm}$ for ${ }^{208} \mathrm{~Pb} /{ }^{204} \mathrm{~Pb}$. For 11 samples, replicates were analysed in two separate analytical sessions and give results that are consistent with that external reproducibility (Table $\mathrm{S} 4$ ).

Full procedural blanks for the sediment leaching were $1.9 \pm 0.7 \mathrm{ng}(1 \sigma, \mathrm{n}=9)$. Blanks analysed for isotopic composition gave average values of ${ }^{206} \mathrm{~Pb} /{ }^{204} \mathrm{~Pb}=18.11 \pm 0.44$, ${ }^{207} \mathrm{~Pb} /{ }^{204} \mathrm{~Pb}=15.56 \pm 0.07$ and ${ }^{208} \mathrm{~Pb} /{ }^{204} \mathrm{~Pb}=37.77 \pm 0.33(1 \sigma, \mathrm{n}=7)$, consistent with $\mathrm{a}$ mixture between sample $\mathrm{Pb}$ and anthropogenic $\mathrm{Pb}$ with an approximately Broken Hill composition (Stacey et al., 1969). Leachate samples typically contained 400-1000 ng Pb, so the blank contribution represents only $0.2-0.5 \%$ of the total $\mathrm{Pb}$. Therefore, no blank correction has been applied. In the smallest samples analysed, which contained $\sim 200 \mathrm{ng} \mathrm{Pb}$, the blank could contribute up to $\sim 1 \%$ of the $\mathrm{Pb}$ and produce an error of $\sim 100 \mathrm{ppm}$ for ${ }^{207} \mathrm{~Pb} /{ }^{204} \mathrm{~Pb}$ and $\sim 400 \mathrm{ppm}$ for ${ }^{206} \mathrm{~Pb} /{ }^{204} \mathrm{~Pb}$ and ${ }^{208} \mathrm{~Pb} /{ }^{204} \mathrm{~Pb}$. This error is comparable to the external analytical reproducibility, and remains negligible in comparison to downcore variability in SK129-CR2, which is $~ 30$ times larger.

\section{Assessing anthropogenic contamination of sediment leachates}

All measured leachate $\mathrm{Pb}$ isotope data from SK129-CR2 (Table S4) are plotted against core depth in Figure $\mathrm{S} 1$ and as $\mathrm{Pb}-\mathrm{Pb}$ plots in Figure $\mathrm{S} 2$. These data reveal changes through time across two full glacial cycles that mostly fall on a binary mixing line in $\mathrm{Pb}-\mathrm{Pb}$ space. Within the depth range from $60-518 \mathrm{~cm}$, most samples form a relatively smooth pattern of temporal variability, but six samples out of 82 fall significantly outside of that smooth pattern, in each case towards less radiogenic $\mathrm{Pb}$ isotopic compositions (Figure $\mathrm{S} 1$ ). These samples also lie significantly away from the binary mixing line defined by the other samples in ${ }^{207} \mathrm{~Pb} /{ }^{204} \mathrm{~Pb} \mathrm{v}{ }^{206} \mathrm{~Pb} /{ }^{204} \mathrm{~Pb}$ space (Figure $\mathrm{S} 2$ ), with higher ${ }^{207} \mathrm{~Pb} /{ }^{204} \mathrm{~Pb}$ for a given ${ }^{206} \mathrm{~Pb} /{ }^{204} \mathrm{~Pb}$. In contrast, any such divergence away from binary mixing is less apparent in

${ }^{208} \mathrm{~Pb} /{ }^{204} \mathrm{~Pb} \mathrm{v}{ }^{206} \mathrm{~Pb} /{ }^{204} \mathrm{~Pb}$ space. Together, these observations appear to indicate anthropogenic contamination by a contaminant with approximately the Broken Hill composition (Stacey et al., 1969) (Figure S2), which has been shown to be the main source of anthropogenic $\mathrm{Pb}$ for the $20^{\text {th }}$ century (van de Velde et al., 2005).

Whereas such contamination from 60-518 cm appears to be occasional and distributed randomly, in the upper section of the core $(8-56 \mathrm{~cm})$ the majority of samples appear to deviate away from the binary mixing line, also in a similar direction (Figure S2). This behaviour produces a somewhat spiky time series (Figure S1) and a smaller magnitude of 
deglacial change for Termination I than for the other glacial-interglacial transitions in the record, especially for ${ }^{208} \mathrm{~Pb} /{ }^{204} \mathrm{~Pb}$ and ${ }^{206} \mathrm{~Pb} /{ }^{204} \mathrm{~Pb}$. These observations are also consistent with anthropogenic contamination. However, the amount of contamination that would be required is considerably larger than can be explained by any of our measured procedural blanks (Section 3.3 of the main text) and there is not such a persistent artifact in the remainder of the leachate record. We therefore suggest that the contamination in the $8-56 \mathrm{~cm}$ section of the core likely occurred during coring or core storage and processing, rather than during leaching in the laboratory.

For those samples described above for which we suspect anthropogenic contamination, we have attempted to make a correction by regressing from the Broken Hill composition (Stacey et al., 1969), which is taken to represent the most likely composition for the anthropogenic contaminant, onto the best-fit binary mixing line through the data from the remaining 76 samples (Figure S2). As can be seen in Figure S1, the correction is relatively larger for ${ }^{208} \mathrm{~Pb} /{ }^{204} \mathrm{~Pb}$ and ${ }^{206} \mathrm{~Pb} /{ }^{204} \mathrm{~Pb}$ than for ${ }^{207} \mathrm{~Pb} /{ }^{204} \mathrm{~Pb}$. The corrected data for the $8-56 \mathrm{~cm}$ section show a smoother pattern of change across Termination I (Figure S1) and a similar magnitude of glacial-interglacial variability to that observed at previous terminations. For the other six samples suspected to be contaminated, this correction also leads to a significant improvement, since on average the divergence from the temporal patterns of ${ }^{208} \mathrm{~Pb} /{ }^{204} \mathrm{~Pb}$ and ${ }^{206} \mathrm{~Pb} /{ }^{204} \mathrm{~Pb}$ defined by the remainder of the data is reduced by $\sim 80 \%$ (Figure $\mathrm{S} 1$ ). The apparent improvement of the corrected data over the raw data in terms of autocorrelation between adjacent samples further supports our suggestion of anthropogenic contamination.

Since we are uncertain of the source or isotopic composition of the contaminant, those six outlying data points (Figure S1) are excluded from further discussion. For the $8-56 \mathrm{~cm}$ section of the record, our correction appears reasonably robust and we include the corrected data in Table S5. Those corrected data from 8-56 cm are plotted in the time series plots, but are not plotted in the $\mathrm{Pb}-\mathrm{Pb}$ plots because the mixing trend is well defined by the 76 measured data not requiring a correction.

\section{Sediment leaching reproducibility}

We tested the effect of sample size during leaching (Wilson et al., 2013) in the case of one glacial sample $(328 \mathrm{~cm})$ and one interglacial sample $(434 \mathrm{~cm})$ from SK129-CR2 (Table $\mathrm{S} 4)$. At $328 \mathrm{~cm}$, the smaller sample is less radiogenic by $1000 \mathrm{ppm}, 350 \mathrm{ppm}$ and $550 \mathrm{ppm}$ for ${ }^{206} \mathrm{~Pb} /{ }^{204} \mathrm{~Pb},{ }^{207} \mathrm{~Pb} /{ }^{204} \mathrm{~Pb}$ and ${ }^{208} \mathrm{~Pb} /{ }^{204} \mathrm{~Pb}$ respectively (Figure $\mathrm{S} 1$ ), which is larger than the measurement uncertainty. The direction of change is consistent with a minor volcanic contamination of the smaller sample, as suggested previously for $\mathrm{Nd}$ isotopes (Wilson et al., 2013 ), but the magnitude is only $\sim 10 \%$ of the magnitude of glacial-interglacial $\mathrm{Pb}$ isotope changes. At $434 \mathrm{~cm}$, the smaller sample is instead more radiogenic than the larger sample (Figure S1), which is not the direction expected for volcanic contamination. Since we 
suggested that the large sample at $434 \mathrm{~cm}$ may have been affected by anthropogenic contamination, it is hard to assess the reproducibility related to sample size in this case. Overall, this sample size test should represent a worst case scenario, and suggests that less than $10 \%$ of the glacial-interglacial variability in the record may be explained by leaching systematics.

In a second test, we used low solution/solid ratios to prevent complete decarbonation before $\mathrm{HH}$ leaching on a subset of 9 samples (Table S4). There is excellent agreement for $\mathrm{Pb}$ isotopes between these data and the remainder of the data measured on decarbonated leachates. Given evidence that the use of low solution/solid ratios is a more reliable approach for deep sea authigenic Nd isotope reconstructions (Wilson et al., 2013), this good agreement provides further confidence in our $\mathrm{Pb}$ isotope reconstruction.

Overall, the above tests suggest a generally reliable recovery of the authigenic $\mathrm{Pb}$ isotope signal by sediment leaching in core SK129-CR2, in agreement with a more general mass balance argument that leaching should be more robust for $\mathrm{Pb}$ isotopes than for $\mathrm{Nd}$ isotopes (Gutjahr et al., 2007).

\section{Detrital sediment $\mathrm{Pb}$ isotopic composition of the Lower Meghna}

Sample BGP 21 was collected from the Lower Meghna during the monsoon period and represents the whole silicate fraction of the suspended load. It was leached with $1 \mathrm{M}$ acetic acid to remove authigenic components before dissolution and measurement of its $\mathrm{Pb}$ isotopic composition (Galy and France-Lanord, 2001). Its $\mathrm{Pb}$ isotopic composition is ${ }^{206} \mathrm{~Pb} /{ }^{204} \mathrm{~Pb}=19.297 \pm 0.005,{ }^{207} \mathrm{~Pb} /{ }^{204} \mathrm{~Pb}=15.796 \pm 0.005,{ }^{208} \mathrm{~Pb} /{ }^{204} \mathrm{~Pb}=39.72 \pm 0.01($ all $2 \sigma$ errors). 


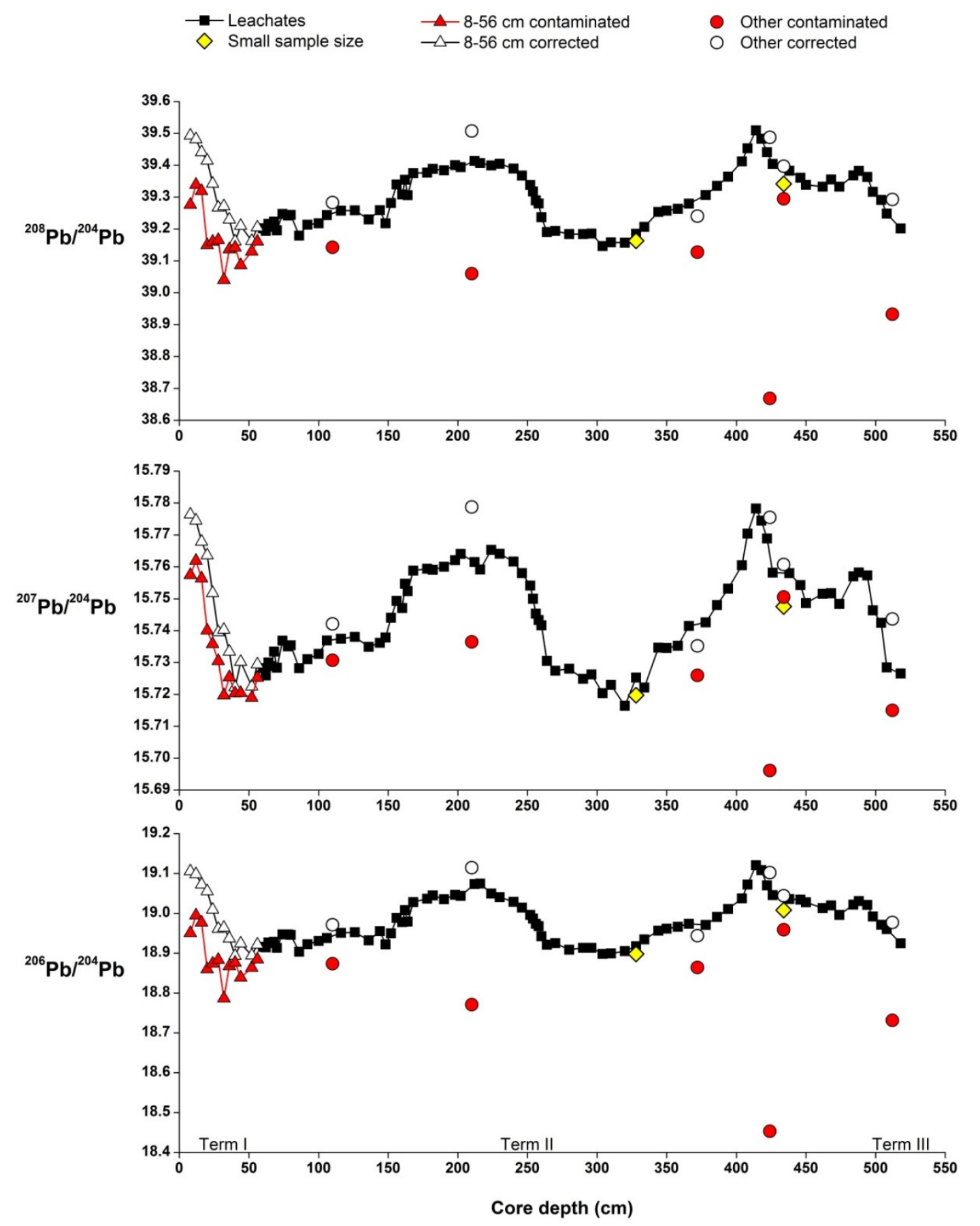

Figure S1: Sediment leachate $\mathrm{Pb}$ isotope data from SK129-CR2 plotted against core depth. Panels show ${ }^{208} \mathrm{~Pb} /{ }^{204} \mathrm{~Pb},{ }^{207} \mathrm{~Pb} /{ }^{204} \mathrm{~Pb}$ and ${ }^{206} \mathrm{~Pb} /{ }^{204} \mathrm{~Pb}$ records. The leachate data considered reliable are plotted as black squares and a line. Small sample size tests at $328 \mathrm{~cm}$ and $434 \mathrm{~cm}$ are plotted as yellow diamonds. Anthropogenic contamination is suspected for the top section of the core $(8-56 \mathrm{~cm})$ and six other samples: the raw data are shown as red triangles and circles, and the data corrected for anthropogenic contamination (assuming a Broken Hill composition; see Figure S2) are shown as white triangles and circles. The approximate position of Terminations I, II and III within the core are shown along the $\mathrm{x}$ axis. 

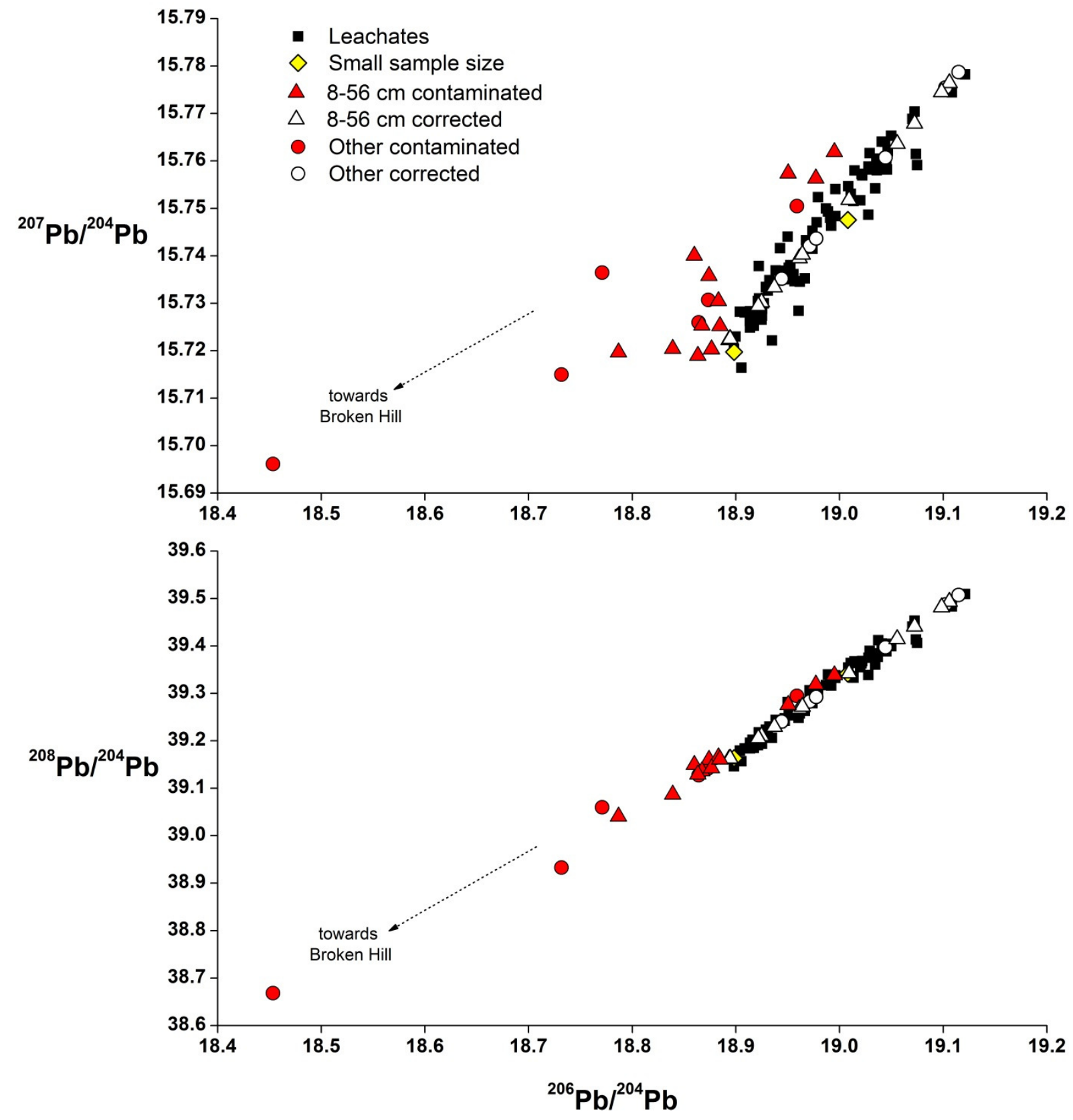

Figure S2: Sediment leachate $\mathrm{Pb}$ isotope data from $\mathrm{SK} 129-\mathrm{CR} 2$ plotted as $\mathrm{Pb}-\mathrm{Pb}$ crossplots: ${ }^{207} \mathrm{~Pb} /{ }^{204} \mathrm{~Pb}$ versus ${ }^{206} \mathrm{~Pb} /{ }^{204} \mathrm{~Pb},{ }^{208} \mathrm{~Pb} /{ }^{204} \mathrm{~Pb}$ versus ${ }^{206} \mathrm{~Pb} /{ }^{204} \mathrm{~Pb}$. The leachate data considered reliable are plotted as black squares. Small sample size tests at $328 \mathrm{~cm}$ and $434 \mathrm{~cm}$ are plotted as yellow diamonds. Anthropogenic contamination is suspected for the top section of the core $(0-56 \mathrm{~cm})$ and six other samples: the raw data are shown as red triangles and circles, and the data corrected for anthropogenic contamination (assuming a Broken Hill composition) are shown as white triangles and circles. The arrow indicates the approximate direction of mixing towards an anthropogenic contaminant with the composition of Broken Hill (Stacey et al., 1969), from which the data have been corrected onto the mixing line defined by the reliable data. 
Table S1: Radiocarbon data for SK129-CR2

\begin{tabular}{|c|c|c|c|c|c|c|c|}
\hline Depth & $\begin{array}{c}\text { Sample } \\
\text { (cm) }\end{array}$ & Species & ${ }^{14} \mathbf{C}$ age & error & $\begin{array}{c}{ }^{14} \mathbf{C} \text { age } \\
\text { res. corr. } \\
\text { (yrs) }\end{array}$ & $\begin{array}{c}\text { Calendar } \\
\text { age } \\
\text { (yrs BP) }\end{array}$ & error \\
\hline 2.5 & SUERC-13140 & sacculifer & 3727 & 35 & 3377 & 3616 & 43 \\
\hline 12 & SUERC-13141 & sacculifer & 6039 & 35 & 5689 & 6462 & 39 \\
\hline 18 & SUERC-13142 & sacculifer & 9170 & 35 & 8820 & 9876 & 107 \\
\hline 22 & SUERC-13143 & sacculifer & 9038 & 35 & 8688 & 9618 & 50 \\
\hline 26 & SUERC-13144 & sacculifer & 11896 & 38 & 11546 & 13411 & 59 \\
\hline 30 & SUERC-13147 & sacculifer & 13048 & 39 & 12698 & 14796 & 88 \\
\hline 36 & SUERC-13148 & sacculifer & 14341 & 43 & 13991 & 16320 & 126 \\
\hline 40 & SUERC-13149 & sacculifer & 14117 & 42 & 13767 & 16026 & 118 \\
\hline 44 & SUERC-13150 & sacculifer & 14909 & 44 & 14559 & 17249 & 171 \\
\hline 52 & SUERC-13665 & sacculifer & 17841 & 61 & 17491 & 20677 & 102 \\
\hline 58 & ANU-5020* & menardii & 21580 & 80 & 21230 & 25421 & 129 \\
\hline 64 & SUERC-13669 & sacculifer & 22409 & 94 & 22059 & 26536 & 147 \\
\hline 78 & SUERC-13671 & ruber & 28849 & 189 & 28499 & 33888 & 248 \\
\hline
\end{tabular}

\section{Notes:}

Radiocarbon analysis of planktonic foraminifera at the Scottish Universities Environmental Research Centre (SUERC) AMS Facility (5MV NEC AMS), except for sample at $58 \mathrm{~cm}$ (denoted by *) which was picked by Luke Skinner and run by Stewart Fallon at the Australian National University AMS Lab.

SUERC analyses were funded by grant allocation 1198.1006. Samples were hydrolysed to $\mathrm{CO}_{2}$ using $85 \%$ orthophosphoric acid at $25^{\circ} \mathrm{C}$. The gas was converted to graphite by $\mathrm{Fe} / \mathrm{Zn}$ reduction. The errors are reported as $1 \sigma$. Conversion applied a uniform 350 y reservoir correction (Butzin et al., 2005; Cao et al., 2007) and was converted to calendar years using the Fairbanks et al. (2005) calibration curve 01.07 (see http://radiocarbon.LDEO.columbia.edu). These data were originally presented in Piotrowski et al. (2009), but there was an error in how the reservoir correction was applied which has been corrected here. 
Table S2: Benthic oxygen isotope data from SK129-CR2

\begin{tabular}{|c|c|c|c|c|}
\hline $\begin{array}{l}\text { Depth } \\
\text { (cm) }\end{array}$ & $\begin{array}{c}\text { Age } \\
\text { (ka BP) }\end{array}$ & $\begin{array}{c}\delta^{18} O_{\text {cib }} \\
\text { Piotrowski } \\
\text { et al. } 2009\end{array}$ & $\begin{array}{c}\delta^{18} \mathrm{O}_{\mathrm{Cib}} \\
\text { Wilson et } \\
\text { al. } 2015\end{array}$ & $\begin{array}{c}\delta^{18} O_{\text {cib }} \\
\text { combined }\end{array}$ \\
\hline 0 & 2.28 & 2.88 & & 2.88 \\
\hline 8 & 5.26 & 2.55 & & 2.55 \\
\hline 14 & 7.28 & 2.72 & & 2.72 \\
\hline 16 & 8.10 & 3.31 & & 3.31 \\
\hline 18 & 8.93 & 3.41 & & 3.41 \\
\hline 22 & 10.97 & 3.84 & & 3.84 \\
\hline 24 & 12.19 & 4.01 & & 4.01 \\
\hline 26 & 13.41 & 4.16 & & 4.16 \\
\hline 30 & 14.80 & 4.14 & & 4.14 \\
\hline 32 & 15.14 & 4.04 & & 4.04 \\
\hline 36 & 15.83 & 4.53 & & 4.53 \\
\hline 40 & 16.53 & 4.15 & & 4.15 \\
\hline 44 & 17.25 & 4.16 & & 4.16 \\
\hline 48 & 18.96 & 4.22 & & 4.22 \\
\hline 52 & 20.68 & 4.13 & & 4.13 \\
\hline 56 & 23.84 & 4.20 & & 4.20 \\
\hline 58 & 25.42 & 4.12 & & 4.12 \\
\hline 60 & 25.79 & 3.96 & & 3.96 \\
\hline 62 & 26.16 & 4.10 & & 4.10 \\
\hline 64 & 26.54 & 4.01 & & 4.01 \\
\hline 66 & 27.59 & 4.22 & & 4.22 \\
\hline 68 & 28.64 & 4.24 & & 4.24 \\
\hline 70 & 29.69 & 3.62 & & 3.62 \\
\hline 72 & 30.74 & 3.79 & & 3.79 \\
\hline 74 & 31.79 & 3.77 & & 3.77 \\
\hline 76 & 32.84 & 3.88 & & 3.88 \\
\hline 78 & 33.89 & 3.76 & & 3.76 \\
\hline 80 & 34.89 & 3.78 & & 3.78 \\
\hline 82 & 35.89 & 3.77 & & 3.77 \\
\hline 84 & 36.90 & 3.81 & & 3.81 \\
\hline 86 & 37.90 & 3.93 & & 3.93 \\
\hline 88 & 38.90 & 3.90 & & 3.90 \\
\hline 90 & 39.91 & 3.81 & & 3.81 \\
\hline 92 & 40.91 & 3.93 & & 3.93 \\
\hline 94 & 41.91 & 3.84 & & 3.84 \\
\hline 96 & 42.91 & 3.89 & & 3.89 \\
\hline 98 & 43.92 & 3.53 & & 3.53 \\
\hline 100 & 44.92 & 3.65 & & 3.65 \\
\hline 102 & 45.92 & 3.69 & & 3.69 \\
\hline 104 & 46.93 & 3.67 & & 3.67 \\
\hline 106 & 47.93 & 3.59 & & 3.59 \\
\hline 108 & 48.93 & 3.68 & & 3.68 \\
\hline 110 & 49.93 & 3.76 & & 3.76 \\
\hline 112 & 50.94 & 3.73 & & 3.73 \\
\hline 114 & 51.94 & 3.66 & & 3.66 \\
\hline 116 & 52.94 & 3.80 & & 3.80 \\
\hline 118 & 53.95 & 3.60 & & 3.60 \\
\hline 120 & 54.95 & 3.63 & & 3.63 \\
\hline
\end{tabular}




\begin{tabular}{|c|c|c|c|c|}
\hline 124 & 56.95 & 3.59 & & 3.59 \\
\hline 132 & 60.97 & 3.71 & & 3.71 \\
\hline 140 & 64.98 & 3.94 & & 3.94 \\
\hline 142 & 65.98 & 4.09 & & 4.09 \\
\hline 144 & 66.98 & 4.36 & & 4.36 \\
\hline 146 & 67.99 & 3.98 & & 3.98 \\
\hline 148 & 68.99 & 4.18 & & 4.18 \\
\hline 150 & 69.99 & 3.77 & & 3.77 \\
\hline 152 & 70.99 & 3.87 & & 3.87 \\
\hline 154 & 72.00 & 3.85 & & 3.85 \\
\hline 156 & 73.00 & 3.57 & & 3.57 \\
\hline 160 & 75.00 & 3.38 & & 3.38 \\
\hline 162 & 76.16 & 4.07 & & 4.07 \\
\hline 164 & 77.33 & 3.53 & & 3.53 \\
\hline 166 & 78.49 & 3.28 & & 3.28 \\
\hline 168 & 79.65 & 3.21 & & 3.21 \\
\hline 170 & 80.82 & 3.21 & & 3.21 \\
\hline 172 & 81.98 & 3.41 & & 3.41 \\
\hline 174 & 83.14 & 3.32 & & 3.32 \\
\hline 178 & 85.47 & & 3.33 & 3.33 \\
\hline 186 & 90.12 & 3.42 & & 3.42 \\
\hline 194 & 94.78 & 3.12 & & 3.12 \\
\hline 198 & 97.10 & & 3.21 & 3.21 \\
\hline 210 & 104.08 & 3.15 & & 3.15 \\
\hline 214 & 106.41 & 3.31 & & 3.31 \\
\hline 218 & 108.73 & 3.29 & & 3.29 \\
\hline 222 & 111.06 & 3.45 & & 3.45 \\
\hline 224 & 112.22 & 3.33 & & 3.33 \\
\hline 228 & 114.55 & 2.85 & & 2.85 \\
\hline 232 & 116.88 & 3.08 & & 3.08 \\
\hline 236 & 119.20 & 3.18 & & 3.18 \\
\hline 240 & 121.53 & 2.88 & & 2.88 \\
\hline 242 & 122.69 & 2.71 & & 2.71 \\
\hline 244 & 123.86 & 2.88 & & 2.88 \\
\hline 248 & 126.18 & 3.34 & & 3.34 \\
\hline 250 & 127.35 & 2.70 & & 2.70 \\
\hline 252 & 128.51 & 2.86 & & 2.86 \\
\hline 254 & 129.67 & 2.21 & & 2.21 \\
\hline 256 & 130.84 & 3.44 & & 3.44 \\
\hline 258 & 132.00 & 2.44 & & 2.44 \\
\hline 260 & 132.83 & 3.89 & & 3.89 \\
\hline 262 & 133.66 & 4.21 & & 4.21 \\
\hline 264 & 134.49 & 4.01 & & 4.01 \\
\hline 266 & 135.32 & 4.18 & & 4.18 \\
\hline 270 & 136.99 & 4.13 & & 4.13 \\
\hline 274 & 138.65 & 4.40 & & 4.40 \\
\hline 278 & 140.31 & 4.27 & & 4.27 \\
\hline 282 & 141.97 & 4.14 & & 4.14 \\
\hline 286 & 143.63 & 4.30 & & 4.30 \\
\hline 290 & 145.30 & 4.19 & & 4.19 \\
\hline 294 & 146.96 & 4.11 & & 4.11 \\
\hline 298 & 148.62 & 4.15 & & 4.15 \\
\hline
\end{tabular}




\begin{tabular}{|c|c|c|c|c|}
\hline 300 & 149.45 & 4.17 & & 4.17 \\
\hline 306 & 151.94 & 4.33 & & 4.33 \\
\hline 320 & 157.76 & & 4.13 & 4.13 \\
\hline 326 & 160.25 & & 4.09 & 4.09 \\
\hline 334 & 163.58 & & 3.75 & 3.75 \\
\hline 342 & 166.90 & & 4.11 & 4.11 \\
\hline 344 & 167.73 & & 3.78 & 3.78 \\
\hline 344 & 167.73 & & 3.95 & 3.95 \\
\hline 346 & 168.56 & & 3.80 & 3.80 \\
\hline 350 & 170.23 & & 3.77 & 3.77 \\
\hline 352 & 171.06 & & 3.79 & 3.79 \\
\hline 356 & 172.72 & & 3.78 & 3.78 \\
\hline 358 & 173.55 & & 3.84 & 3.84 \\
\hline 364 & 176.04 & & 3.89 & 3.89 \\
\hline 366 & 176.87 & & 3.89 & 3.89 \\
\hline 374 & 180.20 & & 3.97 & 3.97 \\
\hline 378 & 181.86 & & 3.82 & 3.82 \\
\hline 380 & 182.69 & & 3.63 & 3.63 \\
\hline 382 & 183.52 & & 3.97 & 3.97 \\
\hline 384 & 184.35 & & 3.86 & 3.86 \\
\hline 386 & 185.18 & & 3.91 & 3.91 \\
\hline 390 & 186.85 & & 3.91 & 3.91 \\
\hline 392 & 187.68 & & 3.71 & 3.71 \\
\hline 394 & 188.51 & & 3.84 & 3.84 \\
\hline 396 & 189.34 & & 3.44 & 3.44 \\
\hline 400 & 191.00 & & 3.55 & 3.55 \\
\hline 402 & 192.42 & & 3.21 & 3.21 \\
\hline 402 & 192.42 & & 3.31 & 3.31 \\
\hline 404 & 193.84 & & 3.42 & 3.42 \\
\hline 408 & 196.68 & & 3.28 & 3.28 \\
\hline 410 & 198.11 & & 3.60 & 3.60 \\
\hline 412 & 199.53 & & 3.20 & 3.20 \\
\hline 414 & 200.95 & & 3.18 & 3.18 \\
\hline 416 & 202.37 & & 3.10 & 3.10 \\
\hline 418 & 203.79 & & 3.00 & 3.00 \\
\hline 420 & 205.21 & & 3.06 & 3.06 \\
\hline 422 & 206.63 & & 3.33 & 3.33 \\
\hline 424 & 208.05 & & 3.31 & 3.31 \\
\hline 426 & 209.47 & & 3.17 & 3.17 \\
\hline 426 & 209.47 & & 3.49 & 3.49 \\
\hline 428 & 210.89 & & 3.21 & 3.21 \\
\hline 432 & 213.74 & & 2.97 & 2.97 \\
\hline 438 & 218.00 & & 3.18 & 3.18 \\
\hline 444 & 220.14 & & 3.67 & 3.67 \\
\hline 446 & 220.86 & & 2.93 & 2.93 \\
\hline 450 & 222.29 & & 3.61 & 3.61 \\
\hline 456 & 224.43 & & 3.57 & 3.57 \\
\hline 462 & 226.57 & & 3.48 & 3.48 \\
\hline 468 & 228.71 & & 3.62 & 3.62 \\
\hline 474 & 230.86 & & 3.61 & 3.61 \\
\hline 480 & 233.00 & & 3.40 & 3.40 \\
\hline 484 & 235.40 & & 3.38 & 3.38 \\
\hline
\end{tabular}




\begin{tabular}{|l|l|l|l|l|}
\hline 488 & 237.80 & & 3.11 & $\mathbf{3 . 1 1}$ \\
\hline 490 & 239.00 & & 3.20 & $\mathbf{3 . 2 0}$ \\
\hline 490 & 239.00 & & 3.28 & $\mathbf{3 . 2 8}$ \\
\hline 494 & 241.40 & & 2.78 & $\mathbf{2 . 7 8}$ \\
\hline 498 & 243.80 & & 3.06 & $\mathbf{3 . 0 6}$ \\
\hline 500 & 245.00 & & 3.70 & $\mathbf{3 . 7 0}$ \\
\hline 504 & 246.43 & & 3.90 & $\mathbf{3 . 9 0}$ \\
\hline 508 & 247.86 & & 3.88 & $\mathbf{3 . 8 8}$ \\
\hline 512 & 249.29 & & 3.88 & $\mathbf{3 . 8 8}$ \\
\hline 518 & 251.43 & & 3.88 & $\mathbf{3 . 8 8}$ \\
\hline
\end{tabular}

Notes:

All oxygen isotope data are from C. wuellerstorfi, either from Piotrowski et al. (2009) or Wilson et al. (2015). Measurements were made in the Godwin Laboratory on Cibicidoides wuellerstorfi (>212 $\mu \mathrm{m})$. Foraminifera (typically 2 to 5 specimens) were transferred into sample vials, crushed, and soaked in a solution of $3 \%$ hydrogen peroxide for 30 minutes before being removed. After an acetone ultrasonic bath, the samples were dried at $50{ }^{\circ} \mathrm{C}$ overnight. The samples were analysed using a Micromass Multicarb Sample Preparation System attached to a VG SIRA or VG PRISM mass spectrometer. Each run of 30 samples was accompanied by 10 reference carbonates and 2 control samples. The results are reported with reference to the international standard Vienna PeeDee Belemnite (VPDB) and the precision is better than $\pm 0.08 \%$ for $\delta^{18} \mathrm{O}$. 
Table S3: Age model tie points for SK129-CR2

\begin{tabular}{|c|c|c|c|c|}
\hline $\begin{array}{l}\text { Depth } \\
\text { (cm) }\end{array}$ & $\begin{array}{l}\text { Calendar } \\
\text { age } \\
\text { (ka BP) }\end{array}$ & $\begin{array}{l}\text { Sed rate } \\
\text { below } \\
(\mathrm{cm} / \mathrm{ka})\end{array}$ & Method & Notes \\
\hline 2.5 & 3.616 & 3.34 & ${ }^{14} \mathrm{C}$ & \\
\hline 12 & 6.462 & 2.44 & ${ }^{14} \mathrm{C}$ & \\
\hline 20 & 9.747 & 1.64 & ${ }^{14} \mathrm{C}$ & average of two closely spaced ${ }^{14} \mathrm{C}$ measurements \\
\hline 26 & 13.411 & 2.89 & ${ }^{14} \mathrm{C}$ & \\
\hline 30 & 14.796 & 5.81 & ${ }^{14} \mathrm{C}$ & \\
\hline 38 & 16.173 & 5.58 & ${ }^{14} \mathrm{C}$ & average of two closely spaced ${ }^{14} \mathrm{C}$ measurements \\
\hline 44 & 17.249 & 2.33 & ${ }^{14} \mathrm{C}$ & \\
\hline 52 & 20.677 & 1.26 & ${ }^{14} \mathrm{C}$ & \\
\hline 58 & 25.421 & 5.38 & ${ }^{14} \mathrm{C}$ & \\
\hline 64 & 26.536 & 1.90 & ${ }^{14} \mathrm{C}$ & \\
\hline 78 & 33.888 & 1.99 & ${ }^{14} \mathrm{C}$ & \\
\hline 156 & 73 & 2.00 & MIS 4/5 & \\
\hline 160 & 75 & 1.72 & YTT & first appearance of Youngest Toba Tuff \\
\hline 258 & 132 & 2.41 & MIS 5/6 & \\
\hline 400 & 191 & 1.41 & MIS 6/7 & \\
\hline 438 & 218 & 2.80 & MIS 7.3/7.4 & \\
\hline 480 & 233 & 1.67 & MIS 7.4/7.5 & \\
\hline 500 & 245 & 2.80 & MIS 7/8 & $\begin{array}{l}\text { sedimentation rate below MIS } 7-8 \text { boundary is } \\
\text { unconstrained and based on sedimentation rate in } \\
\text { the subsequent glacial period MIS } 7.4\end{array}$ \\
\hline
\end{tabular}

Notes:

The age model is constrained by radiocarbon dates for 0-34 ka, and thereafter graphical correlation of benthic $\delta^{18} \mathrm{O}$ to the LR04 benthic $\delta^{18} \mathrm{O}$ stack (Lisiecki and Raymo, 2005). The first appearance of the Youngest Toba Tuff (Banakar, 2005; Mark et al., 2014) also provides an independent age estimate that is consistent with the LR04 based age model. 
Table S4: All measured leachate Pb isotope data for SK129-CR2 and ODP 758

\begin{tabular}{|c|c|c|c|c|c|c|c|c|c|c|c|c|c|c|c|}
\hline \multirow[t]{2}{*}{ Core } & \multirow{2}{*}{$\begin{array}{l}\text { Depth } \\
\text { cm }\end{array}$} & \multirow{2}{*}{$\begin{array}{c}\text { Age } \\
\text { ka BP }\end{array}$} & \multirow{2}{*}{$\begin{array}{c}\text { Size } \\
\mathbf{g}\end{array}$} & \multirow{2}{*}{$\begin{array}{l}\text { Number } \\
\text { leaches }\end{array}$} & \multirow[t]{2}{*}{ Notes } & \multicolumn{6}{|c|}{ Measured data } & \multirow{2}{*}{$\begin{array}{l}\text { Anthropogenic } \\
\text { contamination? }\end{array}$} & \multicolumn{3}{|c|}{ Corrected data } \\
\hline & & & & & & $206 / 204$ & $2 \sigma$ & $207 / 204$ & $2 \sigma$ & $208 / 204$ & $2 \sigma$ & & $206 / 204$ & 207/204 & 208/204 \\
\hline SK129-CR2 & 8 & 5.26 & 2.6 & 6 & & 18.9505 & 0.0024 & 15.7574 & 0.0022 & 39.2759 & 0.0063 & possible & 19.1058 & 15.7764 & 39.4934 \\
\hline SK129-CR2 & 12 & 6.46 & 2.3 & 5 & & 18.9950 & 0.0009 & 15.7619 & 0.0011 & 39.3386 & 0.0034 & possible & 19.0983 & 15.7745 & 39.4816 \\
\hline SK129-CR2 & 16 & 8.10 & 2.3 & 6 & & 18.9771 & 0.0024 & 15.7564 & 0.0022 & 39.3190 & 0.0063 & possible & 19.0723 & 15.7679 & 39.4410 \\
\hline SK129-CR2 & 20 & 9.75 & 2.2 & 5 & & 18.8598 & 0.0009 & 15.7401 & 0.0011 & 39.1495 & 0.0034 & possible & 19.0556 & 15.7636 & 39.4147 \\
\hline SK129-CR2 & 24 & 12.19 & 2.2 & 6 & & 18.8740 & 0.0024 & 15.7358 & 0.0022 & 39.1601 & 0.0063 & possible & 19.0093 & 15.7518 & 39.3424 \\
\hline SK129-CR2 & 28 & 14.10 & 2.8 & 5 & & 18.8832 & 0.0009 & 15.7305 & 0.0011 & 39.1654 & 0.0034 & possible & 18.9612 & 15.7395 & 39.2671 \\
\hline SK129-CR2 & 32 & 15.14 & 3.3 & 6 & & 18.7867 & 0.0024 & 15.7197 & 0.0022 & 39.0406 & 0.0063 & possible & 18.9641 & 15.7403 & 39.2718 \\
\hline SK129-CR2 & 36 & 15.83 & 3.1 & 5 & & 18.8672 & 0.0009 & 15.7254 & 0.0011 & 39.1361 & 0.0034 & possible & 18.9371 & 15.7334 & 39.2295 \\
\hline SK129-CR2 & 40 & 16.53 & 1.4 & 6 & & 18.8765 & 0.0024 & 15.7203 & 0.0022 & 39.1422 & 0.0063 & possible & 18.8934 & 15.7222 & 39.1612 \\
\hline SK129-CR2 & 44 & 17.25 & 3.1 & 5 & & 18.8390 & 0.0009 & 15.7204 & 0.0011 & 39.0869 & 0.0034 & possible & 18.9247 & 15.7302 & 39.2100 \\
\hline SK129-CR2 & 52 & 20.68 & 1.4 & 6 & & 18.8632 & 0.0024 & 15.7190 & 0.0022 & 39.1293 & 0.0063 & possible & 18.8944 & 15.7225 & 39.1628 \\
\hline SK129-CR2 & 56 & 23.84 & 3.1 & 5 & & 18.8847 & 0.0009 & 15.7252 & 0.0011 & 39.1608 & 0.0034 & possible & 18.9217 & 15.7294 & 39.2054 \\
\hline SK129-CR2 & 60 & 25.79 & 2.8 & 6 & & 18.9160 & 0.0024 & 15.7282 & 0.0022 & 39.2021 & 0.0063 & & & & \\
\hline SK129-CR2 & 62 & 26.16 & 2.8 & 5 & & 18.9146 & 0.0009 & 15.7260 & 0.0011 & 39.1937 & 0.0034 & & & & \\
\hline SK129-CR2 & 64 & 26.54 & 3.3 & 5 & & 18.9270 & 0.0009 & 15.7300 & 0.0011 & 39.2159 & 0.0034 & & & & \\
\hline SK129-CR2 & 66 & 27.59 & 3.2 & 5 & & 18.9253 & 0.0009 & 15.7289 & 0.0011 & 39.2065 & 0.0034 & & & & \\
\hline SK129-CR2 & 68 & 28.64 & 3.6 & 6 & & 18.9289 & 0.0024 & 15.7334 & 0.0022 & 39.2234 & 0.0063 & & & & \\
\hline SK129-CR2 & 70 & 29.69 & 2.9 & 5 & & 18.9136 & 0.0009 & 15.7283 & 0.0011 & 39.1958 & 0.0034 & & & & \\
\hline SK129-CR2 & 74 & 31.79 & 4.0 & 6 & & 18.9472 & 0.0024 & 15.7369 & 0.0022 & 39.2473 & 0.0063 & & & & \\
\hline SK129-CR2 & 78 & 33.89 & 2.6 & 5 & & 18.9472 & 0.0009 & 15.7350 & 0.0011 & 39.2425 & 0.0034 & & & & \\
\hline SK129-CR2 & 80 & 34.89 & 3.0 & 6 & & 18.9458 & 0.0024 & 15.7354 & 0.0022 & 39.2445 & 0.0063 & & & & \\
\hline SK129-CR2 & 86 & 37.90 & 2.9 & 5 & & 18.9038 & 0.0009 & 15.7282 & 0.0011 & 39.1793 & 0.0034 & & & & \\
\hline SK129-CR2 & 92 & 40.91 & 2.0 & 4 & & 18.9224 & 0.0018 & 15.7310 & 0.0038 & 39.2135 & 0.0082 & & & & \\
\hline SK129-CR2 & 100 & 44.92 & 3.0 & 6 & & 18.9308 & 0.0024 & 15.7327 & 0.0022 & 39.2181 & 0.0063 & & & & \\
\hline SK129-CR2 & 106 & 47.93 & 2.6 & 4 & & 18.9383 & 0.0018 & 15.7369 & 0.0038 & 39.2440 & 0.0082 & & & & \\
\hline SK129-CR2 & 110 & 49.93 & 2.7 & 5 & & 18.8734 & 0.0009 & 15.7307 & 0.0011 & 39.1423 & 0.0034 & contaminated & 18.9713 & 15.7421 & 39.2830 \\
\hline SK129-CR2 & 116 & 52.94 & 2.4 & 6 & & 18.9510 & 0.0024 & 15.7375 & 0.0022 & 39.2574 & 0.0063 & & & & \\
\hline SK129-CR2 & 126 & 57.96 & 2.6 & 4 & & 18.9526 & 0.0018 & 15.7380 & 0.0038 & 39.2585 & 0.0082 & & & & \\
\hline SK129-CR2 & 136 & 62.97 & 4.6 & 5 & & 18.9324 & 0.0009 & 15.7349 & 0.0011 & 39.2299 & 0.0034 & & & & \\
\hline SK129-CR2 & 144 & 66.98 & 4.7 & 5 & & 18.9556 & 0.0009 & 15.7362 & 0.0011 & 39.2590 & 0.0034 & & & & \\
\hline SK129-CR2 & 148 & 68.99 & 4.8 & 6 & & 18.9221 & 0.0024 & 15.7379 & 0.0022 & 39.2177 & 0.0063 & & & & \\
\hline SK129-CR2 & 152 & 70.99 & 4.5 & 5 & & 18.9500 & 0.0009 & 15.7441 & 0.0011 & 39.2813 & 0.0034 & & & & \\
\hline SK129-CR2 & 156 & 73.00 & 5.1 & 6 & & 18.9888 & 0.0024 & 15.7494 & 0.0022 & 39.3399 & 0.0063 & & & & \\
\hline SK129-CR2 & 160 & 75.00 & 4.1 & 5 & & 18.9779 & 0.0009 & 15.7471 & 0.0011 & 39.3086 & 0.0034 & & & & \\
\hline SK129-CR2 & 162 & 76.16 & 3.0 & 6 & & 19.0084 & 0.0024 & 15.7547 & 0.0022 & 39.3546 & 0.0063 & & & & \\
\hline SK129-CR2 & 164 & 77.33 & 3.2 & 5 & & 18.9792 & 0.0009 & 15.7524 & 0.0011 & 39.3061 & 0.0034 & & & & \\
\hline SK129-CR2 & 168 & 79.65 & 2.9 & 6 & & 19.0280 & 0.0024 & 15.7588 & 0.0022 & 39.3750 & 0.0063 & & & & \\
\hline SK129-CR2 & 178 & 85.47 & 6.6 & 5 & & 19.0369 & 0.0018 & 15.7594 & 0.0038 & 39.3770 & 0.0082 & & & & \\
\hline
\end{tabular}




\begin{tabular}{|c|c|c|c|c|c|c|c|c|c|c|c|c|c|c|c|}
\hline SK129-CR2 & 182 & 87.80 & 3.3 & 5 & & 19.0451 & 0.0009 & 15.7590 & 0.0011 & 39.3887 & 0.0034 & & & & \\
\hline SK129-CR2 & 190 & 92.45 & 2.7 & 6 & & 19.0356 & 0.0024 & 15.7600 & 0.0022 & 39.3844 & 0.0063 & & & & \\
\hline SK129-CR2 & 198 & 97.10 & 6.0 & 5 & & 19.0466 & 0.0018 & 15.7621 & 0.0038 & 39.4002 & 0.0082 & & & & \\
\hline SK129-CR2 & 202 & 99.43 & 2.5 & 5 & & 19.0438 & 0.0009 & 15.7640 & 0.0011 & 39.3938 & 0.0034 & & & & \\
\hline SK129-CR2 & 210 & 104.08 & 2.7 & 6 & & 18.7709 & 0.0024 & 15.7365 & 0.0022 & 39.0596 & 0.0063 & contaminated & 19.1149 & 15.7787 & 39.5075 \\
\hline SK129-CR2 & 212 & 105.24 & 1.9 & 5 & & 19.0736 & 0.0018 & 15.7615 & 0.0038 & 39.4134 & 0.0082 & & & & \\
\hline SK129-CR2 & 216 & 107.57 & 1.9 & 5 & & 19.0747 & 0.0018 & 15.7591 & 0.0038 & 39.4065 & 0.0082 & & & & \\
\hline SK129-CR2 & 224 & 112.22 & 2.3 & 5 & & 19.0498 & 0.0018 & 15.7653 & 0.0038 & 39.3995 & 0.0082 & & & & \\
\hline SK129-CR2 & 230 & 115.71 & 3.0 & 6 & & 19.0408 & 0.0024 & 15.7640 & 0.0022 & 39.4050 & 0.0063 & & & & \\
\hline SK129-CR2 & 240 & 121.53 & 3.4 & 6 & & 19.0291 & 0.0024 & 15.7616 & 0.0022 & 39.3897 & 0.0063 & & & & \\
\hline SK129-CR2 & 246 & 125.02 & 2.5 & 5 & & 19.0144 & 0.0009 & 15.7580 & 0.0011 & 39.3677 & 0.0034 & & & & \\
\hline SK129-CR2 & 252 & 128.51 & 2.9 & 5 & & 18.9961 & 0.0009 & 15.7541 & 0.0011 & 39.3380 & 0.0034 & & & & \\
\hline SK129-CR2 & 254 & 129.67 & 3.0 & 6 & & 18.9870 & 0.0024 & 15.7500 & 0.0022 & 39.3175 & 0.0063 & & & & \\
\hline SK129-CR2 & 256 & 130.84 & 2.8 & 5 & & 18.9739 & 0.0009 & 15.7453 & 0.0011 & 39.2897 & 0.0034 & & & & \\
\hline SK129-CR2 & 258 & 132.00 & 2.3 & 6 & & 18.9677 & 0.0024 & 15.7433 & 0.0022 & 39.2800 & 0.0063 & & & & \\
\hline SK129-CR2 & 260 & 132.83 & 2.9 & 5 & & 18.9426 & 0.0009 & 15.7417 & 0.0011 & 39.2369 & 0.0034 & & & & \\
\hline SK129-CR2 & 264 & 134.49 & 3.2 & 6 & & 18.9212 & 0.0024 & 15.7305 & 0.0022 & 39.1907 & 0.0063 & & & & \\
\hline SK129-CR2 & 270 & 136.99 & 3.3 & 6 & & 18.9252 & 0.0024 & 15.7274 & 0.0022 & 39.1940 & 0.0063 & & & & \\
\hline SK129-CR2 & 280 & 141.14 & 2.5 & 4 & & 18.9086 & 0.0018 & 15.7281 & 0.0038 & 39.1840 & 0.0082 & & & & \\
\hline SK129-CR2 & 290 & 145.30 & 2.6 & 4 & & 18.9137 & 0.0018 & 15.7249 & 0.0038 & 39.1840 & 0.0082 & & & & \\
\hline SK129-CR2 & 296 & 147.79 & 2.0 & 4 & & 18.9135 & 0.0018 & 15.7263 & 0.0038 & 39.1855 & 0.0082 & & & & \\
\hline SK129-CR2 & 304 & 151.11 & 2.1 & 4 & & 18.8981 & 0.0018 & 15.7204 & 0.0038 & 39.1463 & 0.0082 & & & & \\
\hline SK129-CR2 & 310 & 153.61 & 2.8 & 4 & & 18.8996 & 0.0018 & 15.7230 & 0.0038 & 39.1583 & 0.0082 & & & & \\
\hline SK129-CR2 & 320 & 157.76 & 3.8 & 9 & & 18.9053 & 0.0012 & 15.7164 & 0.0013 & 39.1571 & 0.0040 & & & & \\
\hline SK129-CR2 & 328 & 161.08 & 4.6 & 10 & $\mathrm{~L}$ & 18.9173 & 0.0010 & 15.7253 & 0.0010 & 39.1849 & 0.0021 & & & & \\
\hline SK129-CR2 & 328 & 161.08 & 1.9 & 10 & $S$ & 18.8983 & 0.0010 & 15.7198 & 0.0010 & 39.1632 & 0.0021 & & & & \\
\hline SK129-CR2 & 334 & 163.58 & 3.4 & 9 & & 18.9348 & 0.0012 & 15.7222 & 0.0013 & 39.2066 & 0.0040 & & & & \\
\hline SK129-CR2 & 344 & 167.73 & 3.0 & 10 & & 18.9565 & 0.0010 & 15.7346 & 0.0010 & 39.2537 & 0.0021 & & & & \\
\hline SK129-CR2 & 350 & 170.23 & 2.7 & 10 & & 18.9617 & 0.0010 & 15.7346 & 0.0010 & 39.2576 & 0.0021 & & & & \\
\hline SK129-CR2 & 358 & 173.55 & 3.2 & 10 & & 18.9665 & 0.0033 & 15.7353 & 0.0031 & 39.2634 & 0.0095 & & & & \\
\hline SK129-CR2 & 358 & 173.55 & 3.2 & 10 & rep & 18.9717 & 0.0034 & 15.7389 & 0.0025 & 39.2769 & 0.0079 & & & & \\
\hline SK129-CR2 & 366 & 176.87 & 2.7 & 9 & & 18.9739 & 0.0012 & 15.7415 & 0.0013 & 39.2794 & 0.0040 & & & & \\
\hline SK129-CR2 & 372 & 179.37 & 6.7 & 5 & * & 18.8642 & 0.0018 & 15.7260 & 0.0038 & 39.1272 & 0.0082 & contaminated & 18.9442 & 15.7352 & 39.2406 \\
\hline SK129-CR2 & 378 & 181.86 & 6.0 & 9 & & 18.9711 & 0.0012 & 15.7426 & 0.0013 & 39.3065 & 0.0040 & & & & \\
\hline SK129-CR2 & 386 & 185.18 & 4.8 & 9 & & 18.9909 & 0.0012 & 15.7480 & 0.0013 & 39.3355 & 0.0040 & & & & \\
\hline SK129-CR2 & 394 & 188.51 & 4.9 & 9 & & 19.0108 & 0.0012 & 15.7531 & 0.0013 & 39.3641 & 0.0040 & & & & \\
\hline SK129-CR2 & 404 & 193.84 & 3.4 & 11 & & 19.0374 & 0.0033 & 15.7604 & 0.0031 & 39.4120 & 0.0095 & & & & \\
\hline SK129-CR2 & 404 & 193.84 & 3.4 & 11 & rep & 19.0361 & 0.0034 & 15.7591 & 0.0025 & 39.4090 & 0.0079 & & & & \\
\hline SK129-CR2 & 408 & 196.68 & 7.0 & 5 & * & 19.0723 & 0.0018 & 15.7704 & 0.0038 & 39.4533 & 0.0082 & & & & \\
\hline SK129-CR2 & 414 & 200.95 & 3.7 & 11 & & 19.1210 & 0.0033 & 15.7783 & 0.0031 & 39.5095 & 0.0095 & & & & \\
\hline SK129-CR2 & 414 & 200.95 & 3.7 & 11 & rep & 19.1214 & 0.0034 & 15.7779 & 0.0025 & 39.5091 & 0.0079 & & & & \\
\hline SK129-CR2 & 418 & 203.79 & 2.4 & 5 & & 19.1083 & 0.0009 & 15.7745 & 0.0011 & 39.4831 & 0.0034 & & & & \\
\hline
\end{tabular}




\begin{tabular}{|c|c|c|c|c|c|c|c|c|c|c|c|c|c|c|c|}
\hline SK129-CR2 & 422 & 206.63 & 7.6 & 5 & * & 19.0702 & 0.0018 & 15.7688 & 0.0038 & 39.4409 & 0.0082 & & & & \\
\hline SK129-CR2 & 424 & 208.05 & 3.6 & 9 & & 18.4534 & 0.0012 & 15.6961 & 0.0013 & 38.6685 & 0.0040 & contaminated & 19.1021 & 15.7755 & 39.4874 \\
\hline SK129-CR2 & 426 & 209.47 & 3.0 & 11 & & 19.0458 & 0.0033 & 15.7582 & 0.0031 & 39.4041 & 0.0095 & & & & \\
\hline SK129-CR2 & 426 & 209.47 & 3.0 & 11 & rep & 19.0465 & 0.0034 & 15.7598 & 0.0025 & 39.4074 & 0.0079 & & & & \\
\hline SK129-CR2 & 434 & 215.16 & 3.0 & 11 & $\mathrm{~L}$ & 18.9589 & 0.0033 & 15.7505 & 0.0031 & 39.2945 & 0.0095 & contaminated & 19.0443 & 15.7607 & 39.3971 \\
\hline SK129-CR2 & 434 & 215.16 & 3.0 & 11 & $L$, rep & 18.9582 & 0.0034 & 15.7493 & 0.0025 & 39.2851 & 0.0079 & contaminated & & & \\
\hline SK129-CR2 & 434 & 215.16 & 1.7 & 11 & $S$ & 19.0081 & 0.0033 & 15.7476 & 0.0031 & 39.3417 & 0.0095 & & & & \\
\hline SK129-CR2 & 434 & 215.16 & 1.7 & 11 & S, rep & 19.0077 & 0.0034 & 15.7469 & 0.0025 & 39.3396 & 0.0079 & & & & \\
\hline SK129-CR2 & 438 & 218.00 & 5.3 & 5 & * & 19.0359 & 0.0018 & 15.7580 & 0.0038 & 39.3829 & 0.0082 & & & & \\
\hline SK129-CR2 & 446 & 220.86 & 6.5 & 5 & * & 19.0344 & 0.0005 & 15.7542 & 0.0016 & 39.3607 & 0.0043 & & & & \\
\hline SK129-CR2 & 450 & 222.29 & 4.7 & 9 & & 19.0279 & 0.0012 & 15.7487 & 0.0013 & 39.3388 & 0.0040 & & & & \\
\hline SK129-CR2 & 462 & 226.57 & 5.5 & 5 & * & 19.0135 & 0.0005 & 15.7516 & 0.0016 & 39.3330 & 0.0043 & & & & \\
\hline SK129-CR2 & 468 & 228.71 & 4.2 & 9 & & 19.0200 & 0.0012 & 15.7517 & 0.0013 & 39.3553 & 0.0040 & & & & \\
\hline SK129-CR2 & 474 & 230.86 & 2.5 & 11 & & 18.9960 & 0.0033 & 15.7484 & 0.0031 & 39.3327 & 0.0095 & & & & \\
\hline SK129-CR2 & 474 & 230.86 & 2.5 & 11 & rep & 19.0002 & 0.0034 & 15.7505 & 0.0025 & 39.3407 & 0.0079 & & & & \\
\hline SK129-CR2 & 484 & 235.40 & 7.9 & 5 & * & 19.0219 & 0.0005 & 15.7570 & 0.0016 & 39.3683 & 0.0043 & & & & \\
\hline SK129-CR2 & 488 & 237.80 & 2.7 & 11 & & 19.0307 & 0.0033 & 15.7582 & 0.0031 & 39.3822 & 0.0095 & & & & \\
\hline SK129-CR2 & 488 & 237.80 & 2.7 & 11 & rep & 19.0295 & 0.0034 & 15.7573 & 0.0025 & 39.3768 & 0.0079 & & & & \\
\hline SK129-CR2 & 494 & 241.40 & 3.0 & 5 & * & 19.0212 & 0.0005 & 15.7573 & 0.0016 & 39.3633 & 0.0043 & & & & \\
\hline SK129-CR2 & 498 & 243.80 & 2.7 & 11 & & 18.9920 & 0.0033 & 15.7464 & 0.0031 & 39.3165 & 0.0095 & & & & \\
\hline SK129-CR2 & 498 & 243.80 & 2.7 & 11 & rep & 18.9924 & 0.0034 & 15.7461 & 0.0025 & 39.3157 & 0.0079 & & & & \\
\hline SK129-CR2 & 504 & 246.43 & 3.2 & 11 & & 18.9714 & 0.0033 & 15.7424 & 0.0031 & 39.2912 & 0.0095 & & & & \\
\hline SK129-CR2 & 504 & 246.43 & 3.2 & 11 & rep & 18.9676 & 0.0034 & 15.7365 & 0.0025 & 39.2719 & 0.0079 & & & & \\
\hline SK129-CR2 & 508 & 247.86 & 1.8 & 9 & & 18.9606 & 0.0012 & 15.7284 & 0.0013 & 39.2484 & 0.0040 & & & & \\
\hline SK129-CR2 & 512 & 249.29 & 3.9 & 11 & & 18.7316 & 0.0033 & 15.7150 & 0.0031 & 38.9328 & 0.0095 & contaminated & 18.9775 & 15.7437 & 39.2926 \\
\hline SK129-CR2 & 512 & 249.29 & 3.9 & 11 & rep & 18.7307 & 0.0034 & 15.7136 & 0.0025 & 38.9286 & 0.0079 & contaminated & & & \\
\hline SK129-CR2 & 518 & 251.43 & 5.6 & 5 & * & 18.9247 & 0.0005 & 15.7266 & 0.0016 & 39.2017 & 0.0043 & & & & \\
\hline ODP 758 A1 H1 67-69 & 67 & 33 & 13.2 & 6 & & 19.0040 & 0.0011 & 15.7391 & 0.0016 & 39.2354 & 0.0049 & & & & \\
\hline ODP 758 A1 H2 64.5-67 & 214.5 & 77 & 7.3 & 6 & & 18.9620 & 0.0011 & 15.7481 & 0.0016 & 39.3243 & 0.0049 & & & & \\
\hline ODP 758 A1 H2 123.5-125.5 & 273.5 & 128 & 9.1 & 6 & & 18.9767 & 0.0011 & 15.7558 & 0.0016 & 39.3633 & 0.0049 & & & & \\
\hline ODP 758 A1 H3 13-15.5 & 313 & 143 & 9.3 & 6 & & 18.8993 & 0.0005 & 15.7258 & 0.0016 & 39.2116 & 0.0043 & & & & \\
\hline ODP 758 A1 H3 94-96 & 394 & 192 & 9.4 & 6 & & 18.9877 & 0.0018 & 15.7515 & 0.0038 & 39.3609 & 0.0082 & & & & \\
\hline ODP 758 A1 H4 8-10 & 458 & 233 & 8.6 & 6 & & 18.9868 & 0.0018 & 15.7544 & 0.0038 & 39.3608 & 0.0082 & & & & \\
\hline ODP 758 A1 H4 37-39 & 487 & 249 & 9.2 & 6 & & 18.9376 & 0.0018 & 15.7389 & 0.0038 & 39.2859 & 0.0082 & & & & \\
\hline
\end{tabular}

Notes:

This table contains all measured data and data after correction for anthropogenic contamination where contamination was suspected.

Core Identifiers for ODP Leg 121 Site 758 are Hole, Core, Type, Section, Interval

Depth

Depth in cm below sea floor

Size (g)

Wet weights after decarbonation

Number leaches

Number of times leached in $\sim 30 \mathrm{~mL}$ acetic acid before $\mathrm{HH}$ leaching 


\section{Mass spectrometry replicate}

\section{possible}

contaminated
Leached using low solution/solid ratios to prevent complete decarbonation before $\mathrm{HH}$ leaching

Samples where a small anthropogenic contamination is suspected; followed by data corrected as described in Supplementary Information

Samples with clear anthropogenic contamination identified; followed by data corrected as described in Supplementary Information

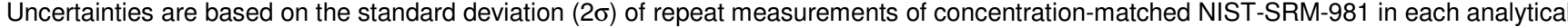
session. Long term reproducibility $(2 \sigma)$ assessed from two internal standards (leachate samples) is $140 \mathrm{ppm}$ for ${ }^{206} \mathrm{~Pb} /{ }^{204} \mathrm{~Pb}, 160 \mathrm{ppm}$ for ${ }^{207} \mathrm{~Pb} /{ }^{204} \mathrm{~Pb}$ and $190 \mathrm{ppm}$ for ${ }^{208} \mathrm{~Pb} /{ }^{204} \mathrm{~Pb}$ 
Table S5: Leachate Pb isotope data for plotting for SK129-CR2

\begin{tabular}{|c|c|c|c|c|c|c|c|c|c|c|}
\hline Core & $\begin{array}{c}\text { Depth } \\
\text { cm } \\
\end{array}$ & $\begin{array}{c}\text { Age } \\
\text { ka BP }\end{array}$ & $\begin{array}{c}\text { Size } \\
\mathbf{g} \\
\end{array}$ & Notes & $206 / 204$ & $2 \sigma$ & $207 / 204$ & $2 \sigma$ & $208 / 204$ & $2 \sigma$ \\
\hline SK129-CR2 & 8 & 5.26 & 2.6 & corrected & 19.1058 & 0.0024 & 15.7764 & 0.0022 & 39.4934 & 0.0063 \\
\hline SK129-CR2 & 12 & 6.46 & 2.3 & corrected & 19.0983 & 0.0009 & 15.7745 & 0.0011 & 39.4816 & 0.0034 \\
\hline SK129-CR2 & 16 & 8.10 & 2.3 & corrected & 19.0723 & 0.0024 & 15.7679 & 0.0022 & 39.4410 & 0.0063 \\
\hline SK129-CR2 & 20 & 9.75 & 2.2 & corrected & 19.0556 & 0.0009 & 15.7636 & 0.0011 & 39.4147 & 0.0034 \\
\hline SK129-CR2 & 24 & 12.19 & 2.2 & corrected & 19.0093 & 0.0024 & 15.7518 & 0.0022 & 39.3424 & 0.0063 \\
\hline SK129-CR2 & 28 & 14.10 & 2.8 & corrected & 18.9612 & 0.0009 & 15.7395 & 0.0011 & 39.2671 & 0.0034 \\
\hline SK129-CR2 & 32 & 15.14 & 3.3 & corrected & 18.9641 & 0.0024 & 15.7403 & 0.0022 & 39.2718 & 0.0063 \\
\hline SK129-CR2 & 36 & 15.83 & 3.1 & corrected & 18.9371 & 0.0009 & 15.7334 & 0.0011 & 39.2295 & 0.0034 \\
\hline SK129-CR2 & 40 & 16.53 & 1.4 & corrected & 18.8934 & 0.0024 & 15.7222 & 0.0022 & 39.1612 & 0.0063 \\
\hline SK129-CR2 & 44 & 17.25 & 3.1 & corrected & 18.9247 & 0.0009 & 15.7302 & 0.0011 & 39.2100 & 0.0034 \\
\hline SK129-CR2 & 52 & 20.68 & 1.4 & corrected & 18.8944 & 0.0024 & 15.7225 & 0.0022 & 39.1628 & 0.0063 \\
\hline SK129-CR2 & 56 & 23.84 & 3.1 & corrected & 18.9217 & 0.0009 & 15.7294 & 0.0011 & 39.2054 & 0.0034 \\
\hline SK129-CR2 & 60 & 25.79 & 2.8 & & 18.9160 & 0.0024 & 15.7282 & 0.0022 & 39.2021 & 0.0063 \\
\hline SK129-CR2 & 62 & 26.16 & 2.8 & & 18.9146 & 0.0009 & 15.7260 & 0.0011 & 39.1937 & 0.0034 \\
\hline SK129-CR2 & 64 & 26.54 & 3.3 & & 18.9270 & 0.0009 & 15.7300 & 0.0011 & 39.2159 & 0.0034 \\
\hline SK129-CR2 & 66 & 27.59 & 3.2 & & 18.9253 & 0.0009 & 15.7289 & 0.0011 & 39.2065 & 0.0034 \\
\hline SK129-CR2 & 68 & 28.64 & 3.6 & & 18.9289 & 0.0024 & 15.7334 & 0.0022 & 39.2234 & 0.0063 \\
\hline SK129-CR2 & 70 & 29.69 & 2.9 & & 18.9136 & 0.0009 & 15.7283 & 0.0011 & 39.1958 & 0.0034 \\
\hline SK129-CR2 & 74 & 31.79 & 4.0 & & 18.9472 & 0.0024 & 15.7369 & 0.0022 & 39.2473 & 0.0063 \\
\hline SK129-CR2 & 78 & 33.89 & 2.6 & & 18.9472 & 0.0009 & 15.7350 & 0.0011 & 39.2425 & 0.0034 \\
\hline SK129-CR2 & 80 & 34.89 & 3.0 & & 18.9458 & 0.0024 & 15.7354 & 0.0022 & 39.2445 & 0.0063 \\
\hline SK129-CR2 & 86 & 37.90 & 2.9 & & 18.9038 & 0.0009 & 15.7282 & 0.0011 & 39.1793 & 0.0034 \\
\hline SK129-CR2 & 92 & 40.91 & 2.0 & & 18.9224 & 0.0018 & 15.7310 & 0.0038 & 39.2135 & 0.0082 \\
\hline SK129-CR2 & 100 & 44.92 & 3.0 & & 18.9308 & 0.0024 & 15.7327 & 0.0022 & 39.2181 & 0.0063 \\
\hline SK129-CR2 & 106 & 47.93 & 2.6 & & 18.9383 & 0.0018 & 15.7369 & 0.0038 & 39.2440 & 0.0082 \\
\hline SK129-CR2 & 116 & 52.94 & 2.4 & & 18.9510 & 0.0024 & 15.7375 & 0.0022 & 39.2574 & 0.0063 \\
\hline SK129-CR2 & 126 & 57.96 & 2.6 & & 18.9526 & 0.0018 & 15.7380 & 0.0038 & 39.2585 & 0.0082 \\
\hline SK129-CR2 & 136 & 62.97 & 4.6 & & 18.9324 & 0.0009 & 15.7349 & 0.0011 & 39.2299 & 0.0034 \\
\hline SK129-CR2 & 144 & 66.98 & 4.7 & & 18.9556 & 0.0009 & 15.7362 & 0.0011 & 39.2590 & 0.0034 \\
\hline SK129-CR2 & 148 & 68.99 & 4.8 & & 18.9221 & 0.0024 & 15.7379 & 0.0022 & 39.2177 & 0.0063 \\
\hline SK129-CR2 & 152 & 70.99 & 4.5 & & 18.9500 & 0.0009 & 15.7441 & 0.0011 & 39.2813 & 0.0034 \\
\hline SK129-CR2 & 156 & 73.00 & 5.1 & & 18.9888 & 0.0024 & 15.7494 & 0.0022 & 39.3399 & 0.0063 \\
\hline SK129-CR2 & 160 & 75.00 & 4.1 & & 18.9779 & 0.0009 & 15.7471 & 0.0011 & 39.3086 & 0.0034 \\
\hline SK129-CR2 & 162 & 76.16 & 3.0 & & 19.0084 & 0.0024 & 15.7547 & 0.0022 & 39.3546 & 0.0063 \\
\hline SK129-CR2 & 164 & 77.33 & 3.2 & & 18.9792 & 0.0009 & 15.7524 & 0.0011 & 39.3061 & 0.0034 \\
\hline SK129-CR2 & 168 & 79.65 & 2.9 & & 19.0280 & 0.0024 & 15.7588 & 0.0022 & 39.3750 & 0.0063 \\
\hline SK129-CR2 & 178 & 85.47 & 6.6 & & 19.0369 & 0.0018 & 15.7594 & 0.0038 & 39.3770 & 0.0082 \\
\hline SK129-CR2 & 182 & 87.80 & 3.3 & & 19.0451 & 0.0009 & 15.7590 & 0.0011 & 39.3887 & 0.0034 \\
\hline SK129-CR2 & 190 & 92.45 & 2.7 & & 19.0356 & 0.0024 & 15.7600 & 0.0022 & 39.3844 & 0.0063 \\
\hline SK129-CR2 & 198 & 97.10 & 6.0 & & 19.0466 & 0.0018 & 15.7621 & 0.0038 & 39.4002 & 0.0082 \\
\hline SK129-CR2 & 202 & 99.43 & 2.5 & & 19.0438 & 0.0009 & 15.7640 & 0.0011 & 39.3938 & 0.0034 \\
\hline SK129-CR2 & 212 & 105.24 & 1.9 & & 19.0736 & 0.0018 & 15.7615 & 0.0038 & 39.4134 & 0.0082 \\
\hline SK129-CR2 & 216 & 107.57 & 1.9 & & 19.0747 & 0.0018 & 15.7591 & 0.0038 & 39.4065 & 0.0082 \\
\hline SK129-CR2 & 224 & 112.22 & 2.3 & & 19.0498 & 0.0018 & 15.7653 & 0.0038 & 39.3995 & 0.0082 \\
\hline SK129-CR2 & 230 & 115.71 & 3.0 & & 19.0408 & 0.0024 & 15.7640 & 0.0022 & 39.4050 & 0.0063 \\
\hline SK129-CR2 & 240 & 121.53 & 3.4 & & 19.0291 & 0.0024 & 15.7616 & 0.0022 & 39.3897 & 0.0063 \\
\hline SK129-CR2 & 246 & 125.02 & 2.5 & & 19.0144 & 0.0009 & 15.7580 & 0.0011 & 39.3677 & 0.0034 \\
\hline
\end{tabular}




\begin{tabular}{|c|c|c|c|c|c|c|c|c|c|}
\hline SK129-CR2 & 252 & 128.51 & 2.9 & 18.9961 & 0.0009 & 15.7541 & 0.0011 & 39.3380 & 0.0034 \\
\hline SK129-CR2 & 254 & 129.67 & 3.0 & 18.9870 & 0.0024 & 15.7500 & 0.0022 & 39.3175 & 0.0063 \\
\hline SK129-CR2 & 256 & 130.84 & 2.8 & 18.9739 & 0.0009 & 15.7453 & 0.0011 & 39.2897 & 0.0034 \\
\hline SK129-CR2 & 258 & 132.00 & 2.3 & 18.9677 & 0.0024 & 15.7433 & 0.0022 & 39.2800 & 0.0063 \\
\hline SK129-CR2 & 260 & 132.83 & 2.9 & 18.9426 & 0.0009 & 15.7417 & 0.0011 & 39.2369 & 0.0034 \\
\hline SK129-CR2 & 264 & 134.49 & 3.2 & 18.9212 & 0.0024 & 15.7305 & 0.0022 & 39.1907 & 0.0063 \\
\hline SK129-CR2 & 270 & 136.99 & 3.3 & 18.9252 & 0.0024 & 15.7274 & 0.0022 & 39.1940 & 0.0063 \\
\hline SK129-CR2 & 280 & 141.14 & 2.5 & 18.9086 & 0.0018 & 15.7281 & 0.0038 & 39.1840 & 0.0082 \\
\hline SK129-CR2 & 290 & 145.30 & 2.6 & 18.9137 & 0.0018 & 15.7249 & 0.0038 & 39.1840 & 0.0082 \\
\hline SK129-CR2 & 296 & 147.79 & 2.0 & 18.9135 & 0.0018 & 15.7263 & 0.0038 & 39.1855 & 0.0082 \\
\hline SK129-CR2 & 304 & 151.11 & 2.1 & 18.8981 & 0.0018 & 15.7204 & 0.0038 & 39.1463 & 0.0082 \\
\hline SK129-CR2 & 310 & 153.61 & 2.8 & 18.8996 & 0.0018 & 15.7230 & 0.0038 & 39.1583 & 0.0082 \\
\hline SK129-CR2 & 320 & 157.76 & 3.8 & 18.9053 & 0.0012 & 15.7164 & 0.0013 & 39.1571 & 0.0040 \\
\hline SK129-CR2 & 328 & 161.08 & 4.6 & 18.9173 & 0.0010 & 15.7253 & 0.0010 & 39.1849 & 0.0021 \\
\hline SK129-CR2 & 334 & 163.58 & 3.4 & 18.9348 & 0.0012 & 15.7222 & 0.0013 & 39.2066 & 0.0040 \\
\hline SK129-CR2 & 344 & 167.73 & 3.0 & 18.9565 & 0.0010 & 15.7346 & 0.0010 & 39.2537 & 0.0021 \\
\hline SK129-CR2 & 350 & 170.23 & 2.7 & 18.9617 & 0.0010 & 15.7346 & 0.0010 & 39.2576 & 0.0021 \\
\hline SK129-CR2 & 358 & 173.55 & 3.2 & 18.9665 & 0.0033 & 15.7353 & 0.0031 & 39.2634 & 0.0095 \\
\hline SK129-CR2 & 366 & 176.87 & 2.7 & 18.9739 & 0.0012 & 15.7415 & 0.0013 & 39.2794 & 0.0040 \\
\hline SK129-CR2 & 378 & 181.86 & 6.0 & 18.9711 & 0.0012 & 15.7426 & 0.0013 & 39.3065 & 0.0040 \\
\hline SK129-CR2 & 386 & 185.18 & 4.8 & 18.9909 & 0.0012 & 15.7480 & 0.0013 & 39.3355 & 0.0040 \\
\hline SK129-CR2 & 394 & 188.51 & 4.9 & 19.0108 & 0.0012 & 15.7531 & 0.0013 & 39.3641 & 0.0040 \\
\hline SK129-CR2 & 404 & 193.84 & 3.4 & 19.0374 & 0.0033 & 15.7604 & 0.0031 & 39.4120 & 0.0095 \\
\hline SK129-CR2 & 408 & 196.68 & 7.0 & 19.0723 & 0.0018 & 15.7704 & 0.0038 & 39.4533 & 0.0082 \\
\hline SK129-CR2 & 414 & 200.95 & 3.7 & 19.1210 & 0.0033 & 15.7783 & 0.0031 & 39.5095 & 0.0095 \\
\hline SK129-CR2 & 418 & 203.79 & 2.4 & 19.1083 & 0.0009 & 15.7745 & 0.0011 & 39.4831 & 0.0034 \\
\hline SK129-CR2 & 422 & 206.63 & 7.6 & 19.0702 & 0.0018 & 15.7688 & 0.0038 & 39.4409 & 0.0082 \\
\hline SK129-CR2 & 426 & 209.47 & 3.0 & 19.0458 & 0.0033 & 15.7582 & 0.0031 & 39.4041 & 0.0095 \\
\hline SK129-CR2 & 438 & 218.00 & 5.3 & 19.0359 & 0.0018 & 15.7580 & 0.0038 & 39.3829 & 0.0082 \\
\hline SK129-CR2 & 446 & 220.86 & 6.5 & 19.0344 & 0.0005 & 15.7542 & 0.0016 & 39.3607 & 0.0043 \\
\hline SK129-CR2 & 450 & 222.29 & 4.7 & 19.0279 & 0.0012 & 15.7487 & 0.0013 & 39.3388 & 0.0040 \\
\hline SK129-CR2 & 462 & 226.57 & 5.5 & 19.0135 & 0.0005 & 15.7516 & 0.0016 & 39.3330 & 0.0043 \\
\hline SK129-CR2 & 468 & 228.71 & 4.2 & 19.0200 & 0.0012 & 15.7517 & 0.0013 & 39.3553 & 0.0040 \\
\hline SK129-CR2 & 474 & 230.86 & 2.5 & 18.9960 & 0.0033 & 15.7484 & 0.0031 & 39.3327 & 0.0095 \\
\hline SK129-CR2 & 484 & 235.40 & 7.9 & 19.0219 & 0.0005 & 15.7570 & 0.0016 & 39.3683 & 0.0043 \\
\hline SK129-CR2 & 488 & 237.80 & 2.7 & 19.0307 & 0.0033 & 15.7582 & 0.0031 & 39.3822 & 0.0095 \\
\hline SK129-CR2 & 494 & 241.40 & 3.0 & 19.0212 & 0.0005 & 15.7573 & 0.0016 & 39.3633 & 0.0043 \\
\hline SK129-CR2 & 498 & 243.80 & 2.7 & 18.9920 & 0.0033 & 15.7464 & 0.0031 & 39.3165 & 0.0095 \\
\hline SK129-CR2 & 504 & 246.43 & 3.2 & 18.9714 & 0.0033 & 15.7424 & 0.0031 & 39.2912 & 0.0095 \\
\hline SK129-CR2 & 508 & 247.86 & 1.8 & 18.9606 & 0.0012 & 15.7284 & 0.0013 & 39.2484 & 0.0040 \\
\hline SK129-CR2 & 518 & 251.43 & 5.6 & 18.9247 & 0.0005 & 15.7266 & 0.0016 & 39.2017 & 0.0043 \\
\hline
\end{tabular}

Notes:

This table contains the data considered reliable and most appropriate for plotting.

Replicate data (rep in Table S4) and data from small samples (S in Table S4) have been removed.

Where anthropogenic contamination was identified (contaminated in Table S4) the data have also been removed.

For 8-56 cm the data included here are the data corrected for minor anthropogenic contamination.

Uncertainties are based on the standard deviation $(2 \sigma)$ of repeat measurements of concentration matched NIST-SRM-981 in each analytical session. Long term reproducibility $(2 \sigma)$ assessed from two internal leachate samples is $140 \mathrm{ppm}$ for ${ }^{206} \mathrm{~Pb} /{ }^{204} \mathrm{~Pb}, 160 \mathrm{ppm}$ for ${ }^{207} \mathrm{~Pb} /{ }^{204} \mathrm{~Pb}$ and $190 \mathrm{ppm}$ for ${ }^{208} \mathrm{~Pb} /{ }^{204} \mathrm{~Pb}$ 


\section{Supplementary references}

Abouchami, W., Galer, S.J.G., Hofmann, A.W., 2000. High precision lead isotope systematics of lavas from the Hawaiian Scientific Drilling Project. Chemical Geology 169, 187-209.

Banakar, V.K., 2005. $\delta^{13} \mathrm{C}$ depleted oceans before the Termination 2: More nutrient-rich deep-water formation or light-carbon transfer? Indian J. Mar. Sci. 34, 249-258.

Belshaw, N.S., Freedman, P.A., O'Nions, R.K., Frank, M., Guo, Y., 1998. A new variable dispersion double-focusing plasma mass spectrometer with performance illustrated for $\mathrm{Pb}$ isotopes. Int. J. Mass Spectrom. 181, 51-58.

Butzin, M., Prange, M., Lohmann, G., 2005. Radiocarbon simulations for the glacial ocean: The effects of wind stress, Southern Ocean sea ice and Heinrich events. Earth Planet. Sci. Lett. 235, 45-61.

Cao, L., Fairbanks, R.G., Mortlock, R.A., Risk, M.J., 2007. Radiocarbon reservoir age of high latitude North Atlantic surface water during the last deglacial. Quat. Sci. Rev. 26, 732-742.

Fairbanks, R.G., Mortlock, R.A., Chiu, T.C., Cao, L., Kaplan, A., Guilderson, T.P., Fairbanks, T.W., Bloom, A.L., Grootes, P.M., Nadeau, M.J., 2005. Radiocarbon calibration curve spanning 0 to 50,000 years BP based on paired ${ }^{230} \mathrm{Th} /{ }^{234} \mathrm{U} /{ }^{238} \mathrm{U}$ and ${ }^{14} \mathrm{C}$ dates on pristine corals. Quat. Sci. Rev. 24, 17811796.

Galer, S.J.G., Abouchami, W., 1998. Practical application of lead triple spiking for correction of instrumental mass discrimination. Mineralogical Magazine 62A, 491-492.

Galy, A., France-Lanord, C., 2001. Higher erosion rates in the Himalaya: Geochemical constraints on riverine fluxes. Geology 29, 23-26.

Gutjahr, M., Frank, M., Stirling, C.H., Klemm, V., van de Flierdt, T., Halliday, A.N., 2007. Reliable extraction of a deepwater trace metal isotope signal from Fe-Mn oxyhydroxide coatings of marine sediments. Chemical Geology 242, 351-370.

Hirata, T., 1996. Lead isotopic analyses of NIST standard reference materials using multiple collector inductively coupled plasma mass spectrometry coupled with a modified external correction method for mass discrimination effect. Analyst 121, 1407-1411.

Kamenov, G.D., Mueller, P.A., Perfit, M.R., 2004. Optimization of mixed Pb-Tl solutions for high precision isotopic analyses by MC-ICP-MS. J. Anal. At. Spectrom. 19, 1262-1267.

Lisiecki, L.E., Raymo, M.E., 2005. A Pliocene-Pleistocene stack of 57 globally distributed benthic $\delta^{18}$ O records. Paleoceanography 20, doi: 10.1029/2004pa001071.

Mark, D.F., Petraglia, M., Smith, V.C., Morgan, L.E., Barfod, D.N., Ellis, B.S., Pearce, N.J., Pal, J.N., Korisettar, R., 2014. A high-precision ${ }^{40} \mathrm{Ar} /{ }^{39} \mathrm{Ar}$ age for the Young Toba Tuff and dating of ultra-distal tephra: forcing of Quaternary climate and implications for hominin occupation of India. Quaternary Geochronology 21, 90-103.

Piotrowski, A.M., Banakar, V.K., Scrivner, A.E., Elderfield, H., Galy, A., Dennis, A., 2009. Indian Ocean circulation and productivity during the last glacial cycle. Earth Planet. Sci. Lett. 285, 179-189.

Rehkamper, M., Mezger, K., 2000. Investigation of matrix effects for Pb isotope ratio measurements by multiple collector ICP-MS: verification and application of optimized analytical protocols. J. Anal. At. Spectrom. 15, 1451-1460. 
Stacey, J.S., Delevaux, M.E., Ulrych, T.J., 1969. Some triple-filament lead isotope ratio measurements and an absolute growth curve for single-stage leads. Earth Planet. Sci. Lett. 6, 15-25.

van de Velde, K., Vallelonga, P., Candelone, J.P., Rosman, K.J.R., Gaspari, V., Cozzi, G., Barbante, C., Udisti, R., Cescon, P., Boutron, C.F., 2005. Pb isotope record over one century in snow from Victoria Land, Antarctica. Earth Planet. Sci. Lett. 232, 95-108.

Wilson, D.J., Piotrowski, A.M., Galy, A., Banakar, V.K., 2015. Interhemispheric controls on deep ocean circulation and carbon chemistry during the last two glacial cycles. Paleoceanography, doi: $10.1002 / 2014 \mathrm{pa} 002707$

Wilson, D.J., Piotrowski, A.M., Galy, A., Clegg, J.A., 2013. Reactivity of neodymium carriers in deep sea sediments: Implications for boundary exchange and paleoceanography. Geochim. Cosmochim. Acta 109, 197-221. 